\title{
Recent Progress on Electroactive Polymers: Synthesis, Properties and Applications
}

\author{
Md Hafizur Rahman, Harmony Werth, Alexander Goldman, Yuki Hida, Court Diesner, Logan Lane \\ and Pradeep L. Menezes *(D)
}

check for

updates

Citation: Rahman, M.H.; Werth, H.; Goldman, A.; Hida, Y.; Diesner, C.;

Lane, L.; Menezes, P.L. Recent

Progress on Electroactive Polymers:

Synthesis, Properties and

Applications. Ceramics 2021, 4 ,

516-541. https://doi.org/

10.3390 /ceramics4030038

Academic Editors: Giuseppe Viola and Gilbert Fantozzi

Received: 11 July 2021

Accepted: 8 September 2021

Published: 20 September 2021

Publisher's Note: MDPI stays neutral with regard to jurisdictional claims in published maps and institutional affiliations.

Copyright: (c) 2021 by the authors. Licensee MDPI, Basel, Switzerland. This article is an open access article distributed under the terms and conditions of the Creative Commons Attribution (CC BY) license (https:// creativecommons.org/licenses/by/ $4.0 /)$.
Department of Mechanical Engineering, University of Nevada-Reno, Reno, NV 89557, USA; mdhafizurr@unr.edu (M.H.R.); harmswerth@nevada.unr.edu (H.W.); alexandergoldman@nevada.unr.edu (A.G.); yhida0610@gmail.com (Y.H.); Courtdiesner@nevada.unr.edu (C.D.); loganlane@nevada.unr.edu (L.L.)

* Correspondence: pmenezes@unr.edu

\begin{abstract}
Electroactive polymers (EAPs) are an advanced family of polymers that change their shape through electric stimulation and have been a point of interest since their inception. This unique functionality has helped EAPs to contribute to versatile fields, such as electrical, biomedical, and robotics, to name a few. Ionic EAPs have a significant advantage over electronic EAPs. For example, Ionic EAPs require a lower voltage to activate than electronic EAPs. On the other hand, electronic EAPs could generate a relatively larger actuation force. Therefore, efforts have been focused on improving both kinds to achieve superior properties. In this review, the synthesis routes of different EAP-based actuators and their properties are discussed. Moreover, their mechanical interactions have been investigated from a tribological perspective as all these EAPs undergo surface interactions. Such interactions could reduce their useful life and need significant research attention for enhancing their life. Recent advancements and numerous applications of EAPs in various sectors are also discussed in this review.
\end{abstract}

Keywords: actuator; electroactive; ionic; polymer; tribology

\section{Introduction}

Electroactive polymers (EAPs) are a versatile class of electrically deformable polymers. These polymers have the ability to deform when excited by electrical potentials [1] due to their inherent electro-mechanical properties [2]. The piezoelectric couplings in EAPs provide them with unique capabilities that are of significant interest in actuators and soft robotics [3]. Additionally, their ability to transform an electrical stimulus into a mechanical response has the potential to develop biocompatible artificial muscles. Furthermore, EAPs have become an attractive material for wearable sensors and biomimetics. Due to their versatile applications, EAPs are of significant interest for research innovation in the mechano-electrical sector of late $[4,5]$.

Electroactive polymers could be split between two major types depending on how they are produced: electronic EAPs and ionic EAPs. Electronic EAPs, such as dielectric elastomers, mechanically respond to the changes in electrical charge, typically by expansion. Similarly, ionic EAPs can be activated by an electric field that causes deformation due to ion movement. Comparatively, ionic EAPs require a lower voltage than electronic EAPs for activation and therefore have received repeated attention in the literature [6]. On the other hand, electronic EAPs have progressed significantly, and there are different types of electric EAPs already present in the market. Statistically, the overall market of the electroactive polymer was approximately $\$ 3.51$ billion in 2017 , which is projected to be 5.12 billion by 2022 [7].

One major advantage of EAP is that the amount of strain these materials may experience is much higher than what many conventional mechanical actuators would allow [8]. Therefore, EAPs have significant usage in the development of organic actuators, which are 
highly desirable in prosthetics. Due to their biocompatible makeup, flexibility, and light weight, EAPs are a potential candidate for artificial muscle [9]. Also, EAPs stand to benefit the field of soft robotics. The use of soft actuators eliminates some safety concerns that are present when traditional robots interact with humans or delicate tools. Since soft robots tend to be lighter and more compliant, they are less likely to apply crushing forces [10]. Beyond being able to control the movement of EAPs, their adaptability allows for novel robotic motions, such as a snake-shaped robot travelling in a serpentine path [11]. Dielectric elastomers, known for their high deformability and ease of production, could be useful in these types of robotic applications. Other types of applications, such as underwater or in corrosive environments, could benefit from the use of EAPs [12]. EAPs can be designed as a noiseless propulsion devise, which is beneficial to marine organisms that may be damaged by loud noises. Additionally, a soft robot made with EAPs would be less likely to cause catastrophic failure or corrosion in the event of a collision. Lastly, wearable electronics may have a variety of uses for EAPs. Wearable devices often require small electronics for nuanced applications, such as implanted or surface-mounted sensors [12]. EAPS could be used in such applications.

In addition to the afore-mentioned potential of EAPs, there are several aspects that require further development. For instance, EAPs often tend to require a large voltage for activation, a drawback that can lead to various problems such as unnecessary heating and battery consumption that results from increasing the power supply [5]. These issues could lead to material degradation, an adverse effect in terms of tribology. Tribological study of EAPs is an important topic that could help to develop more efficient EAPs in the future. For example, a quick response electroactive polymer could quickly deform to break the interfacial bond and reduce the coefficient of friction [5]. Minimizing friction and wear can increase the service life of the EAP-made objects. All of these aspects could contribute to the advancement of future technology in the field of EAPs. For products and materials that already exist, it is important to seek ways in which they may be improved. In this regard, it is possible to coat an object with an EAP-based material to change its external properties [13]. These modifications can lead to an increase in the electrochemical capacitance, corrosion protection, stabilization of oxide surfaces, and variations of the friction coefficient. For biomedical applications, it is possible to release drug chemicals in a controlled manner.

Between 2017 and 2022, the market of EAP has a projected Compound Annual Growth Rate (CAGR) of 7.9\% [7]. Within this forecast period, materials such as polythiophenes, polyanilines, polypyrroles, and polyacetylenes are going to lead the market of EAP [14]. These are different types of ionic EAPs, also known as inherently conductive polymers. Currently, a lot of research is ongoing for the synthesis and development of ionic EAP. However, a comprehensive review of the synthesis process of ionic EAPs, along with their properties and application, is not available in the literature, to the best of our knowledge. Similarly, electronic EAPs have been at the forefront of electroactive polymer research. In this review, different types of synthesis for EAPs are compared and contrasted, and their effects on the electro-mechanical properties are discussed. Besides, the recent progress and challenges of both ionic and electronic EAPs are highlighted based on the state-of-art literature.

\section{Different Types of EAPs}

Electroactive polymers are typically divided into two categories. One is ionic EAPs, and the other one is electronic EAPs. Each of these divisions can be further sub-divided into multiple branches, as shown in Figure 1. In this review, four types of popular subdivisions of each category are going to be discussed. Moreover, some EAPs have also been developed incorporating both ionic and electronic EAPs to obtain specific advantages. This review will present a brief overview of various EAPs, and discuss their properties, applications, and challenges. In the following subsections, the synthesis routes of different ionic EAPs are depicted with schematic illustrations. 


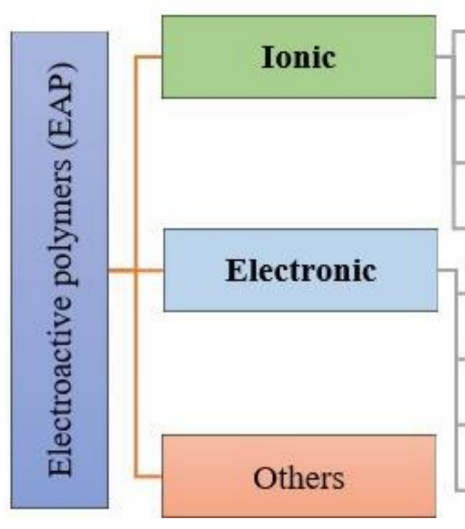

Ionic polymer metal composite (IPMC)

\begin{tabular}{|c|}
\hline Conductive polymer (CP) \\
\hline Ionic polymer gel (IPG) \\
\hline Electrorheological fluids (ERF) \\
\hline Dielectric \\
\hline Electrostrictive \\
\hline Electro-viscoelastic \\
\hline Ferroelectric \\
\hline
\end{tabular}

Figure 1. Different types of electroactive polymers.

\subsection{Ionic Electroactive Polymers}

The ionic EAPs are one of the most common types of electroactive polymers. They require a lower voltage to activate compared to other EAPs since the diffusion of ions drives them. These sort of ionic EAPs can demonstrate a sharp bending angle, which helps them to mimic the natural movement of muscle more precisely. A diagram of an ionic EAP's trilayer actuator structure is shown in Figure 2, with a membrane to facilitate ion exchange sandwiched between two electrodes. Here, the membrane contains dissolved cations. When the ionic EAP is exposed to an electric field, the hydrated cations move toward the negatively charged electrode, causing a localized change in volume. This volume change results in a characteristic bending motion in the ionic EAP [15]. Block copolymer in between the conducting polymers contains the ionic liquids, one kind of electrolyte, comprised of big and bulky cation-anion moiety. The bending angle is tunable. For example, a conductive polymer (CP) actuator made of PEDOT:PSS, was able to reach a sharp bending angle above $90^{\circ}$ [16]. Additionally, when the ionic EAP is bent by external means, it generates an electric signal, meaning that the ionic EAP can be used as both an actuator and a sensor [17].

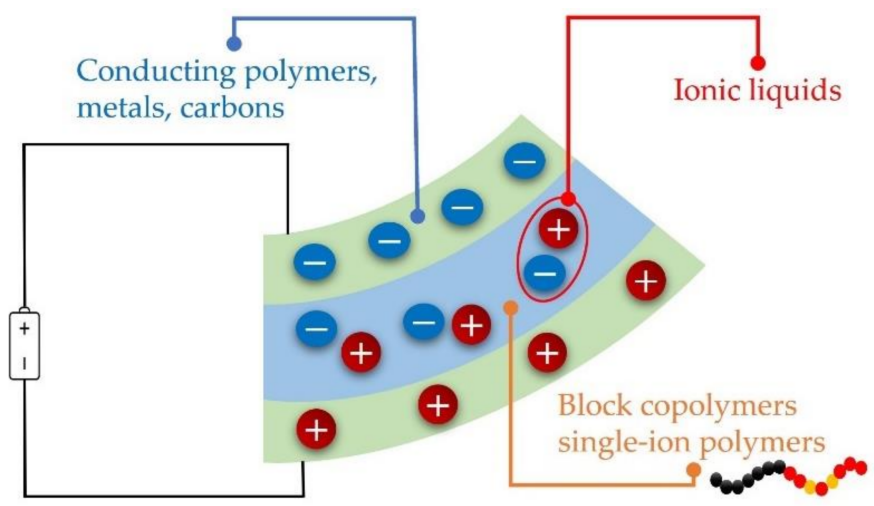

Figure 2. Composition of an ionic EAP actuator with an ionic liquid in the center and electrodes on either side (Redrawn with permission from [18]. Copyright Royal Society of Chemistry, 2018).

There are multiple routes to produce ionic EAPs using different materials. Based on these routes, ionic EAPs could be subdivided into several categories, such as ionic polymer-metal composites (IPMCs), conductive polymers (CPs), ionic polymer gels (IPGs), and electrorheological fluids (ERFs) [18]. It is important to note that these categories are not rigid. Instead, they are often combined into new ionic EAPs as their properties are explored and understood. The following sections detail the synthesis steps of several ionic EAPs that fit into one or more of the above-mentioned categories. 


\subsubsection{Ionic Polymer-Metal Composites (IPMCs)}

Ionic polymer-metal composites (IPMCs) are one of the most prominent categories of ionic EAPs. Figure 3 represents a synthesis method for IPMCs. The most well-known synthesis of IPMCs uses Nafion ${ }^{\circledR}$, a commercially available non-conductive membrane made of a sulfonated tetrafluoroethylene-based fluoropolymer-copolymer (C7HF13O5S-C2F4). Ionic liquids (ILs), a prominent class of chemicals formed with bulky anion and cations (Figure 2), could be used in this process as well [18-20]. Nafion ${ }^{\circledR}$ is often soaked in ionic liquids (ILs) to facilitate ion exchange. While in solution, electrodes are added by electroless plating. Typically, platinum electrodes are used due to their good conductivity, although other conductive materials can be used as well. Electroless plating facilitates the deposition of a metal coating through chemical reduction rather than passing an electric current through the solution. This synthesis method of IPMCs is based on four main steps (Figure 3): preparation of membrane, preparation of electrode, the first reduction reaction, and the second reduction reaction [21].

In the first step, the surface area of the Nafion ${ }^{\circledR}$ membrane is increased by roughening the surface using sandpaper. It is then sonicated in distilled water (DW) for $15 \mathrm{~min}$ to clean the surface, boiled in $1 \mathrm{M} \mathrm{HCl}$ for $30 \mathrm{~min}$, then sonicated in DW for another $30 \mathrm{~min}$. During the preparation of the electrode, the Nafion ${ }^{\circledR}$ membrane is soaked in a solution (A) of Pt salt $\left[\mathrm{Pt}\left(\mathrm{NH}_{3}\right)_{4} \mathrm{Cl}_{2}\right.$ ], ammonium hydroxide $(\mathrm{NH} 4 \mathrm{OH})$ and $\mathrm{DW}$ for between 12 to $48 \mathrm{~h}$, depending on the experimental design. Then it is rinsed with DW. In order to attach the electrode, $\mathrm{Pt}$ ions must be reduced to Pt particles on the surface of the Nafion ${ }^{\circledR}$ membrane [22]. In this step, the membrane is placed into DW at $40{ }^{\circ} \mathrm{C}$, and Sodium borohydride $\left(\mathrm{NaBH}_{4}\right)$ is added. Over the course of $2 \mathrm{~h}$, the temperature is gradually increased to $60^{\circ} \mathrm{C}$. Then, more $\mathrm{NaBH}_{4}$ is added, and the solution is stirred for $1.5 \mathrm{~h}$ while maintaining the temperature at $60^{\circ} \mathrm{C}$. The membrane is then rinsed once again with $\mathrm{DW}$, followed by soaking in $\mathrm{HCl}$ for $1 \mathrm{~h}$. Finally, the second reduction process ensures that more Pt particles grow on the initial layer in order to reduce surface resistivity. In this last step, the membrane is soaked in a solution of $\mathrm{Pt}$ salt and $\mathrm{NH}_{4} \mathrm{OH}$. The solution is then brought to $40{ }^{\circ} \mathrm{C}$. Over the next $4 \mathrm{~h}$, the temperature of the solution is gradually raised to $60^{\circ} \mathrm{C}$. During this 4 -h period, a solution of hydroxylamine hydrochloride $\left(\mathrm{NH}_{2} \mathrm{OH} \cdot \mathrm{HCl}\right)$ and hydrazine monohydrate $\left(\mathrm{NH}_{2} \mathrm{NH}_{2} \mathrm{H}_{2} \mathrm{O}\right)$ should be added every $30 \mathrm{~min}$. Close at the end of the $4 \mathrm{~h}$, the endpoint is checked by adding $\mathrm{NaBH}_{4}$ (reducing agent) [23] to the solution (A) sample that the membrane was soaked in [22]. The membrane can then be cut into strips as needed [22,23]. The schematic of the synthesis process is shown in Figure 3. Notably, this type of ionic EAP has multiple drawbacks due to its construction, such as the high cost of the metals that form the electrodes. Additionally, IPMC actuators often struggle to operate in the air for long periods of time as they become dehydrated [24].

\subsubsection{Conducting Polymers (CPs)}

Conducting Polymers (CPs) represent another area of interest in ionic EAPs. CPs are organic polymers capable of conduct electricity. A CP actuator is produced by forming a trilayer actuator structure with a membrane in the center for ion exchange and CPs as the electrodes. Multiple types of CPs have been investigated for this purpose [25-27]. A conductive polymer could be prepared with a Nafion ${ }^{\circledR}$ membrane and polypyrrole (Ppy) using similar steps to those described previously for IPMCs, as noticeable in Figure 3. For example, to prepare a $\mathrm{CP}$ actuator with a Nafion ${ }^{\circledR}$ membrane, the membrane is roughened, sonicated in DW for $15 \mathrm{~min}$ to clean the surface, boiled in $1 \mathrm{M} \mathrm{HCl}$ for $30 \mathrm{~min}$, then sonicated in DW for another $30 \mathrm{~min}$. The Nafion ${ }^{\circledR}$ membrane is then dipped into a solution of $0.2 \mathrm{M}$ pyrrole with $0.005 \mathrm{M}$ naphthalene-1,5-disulfonic acid disodium salt (NDSA). Then, a solution of $0.2 \mathrm{M} \mathrm{FeCl} 3$ is added while stirring. The mixture is allowed to react overnight and is then washed with DW [28]. Similarly to IPMCs, Nafion ${ }^{\circledR}$ is useful as a membrane in $\mathrm{CP}$ actuators because it is commercially available and nontoxic. However, it can present challenges of delamination after extensive use or after use at high voltages, meaning that the electrodes can detach and then render the CP actuator nonfunctional [29]. 


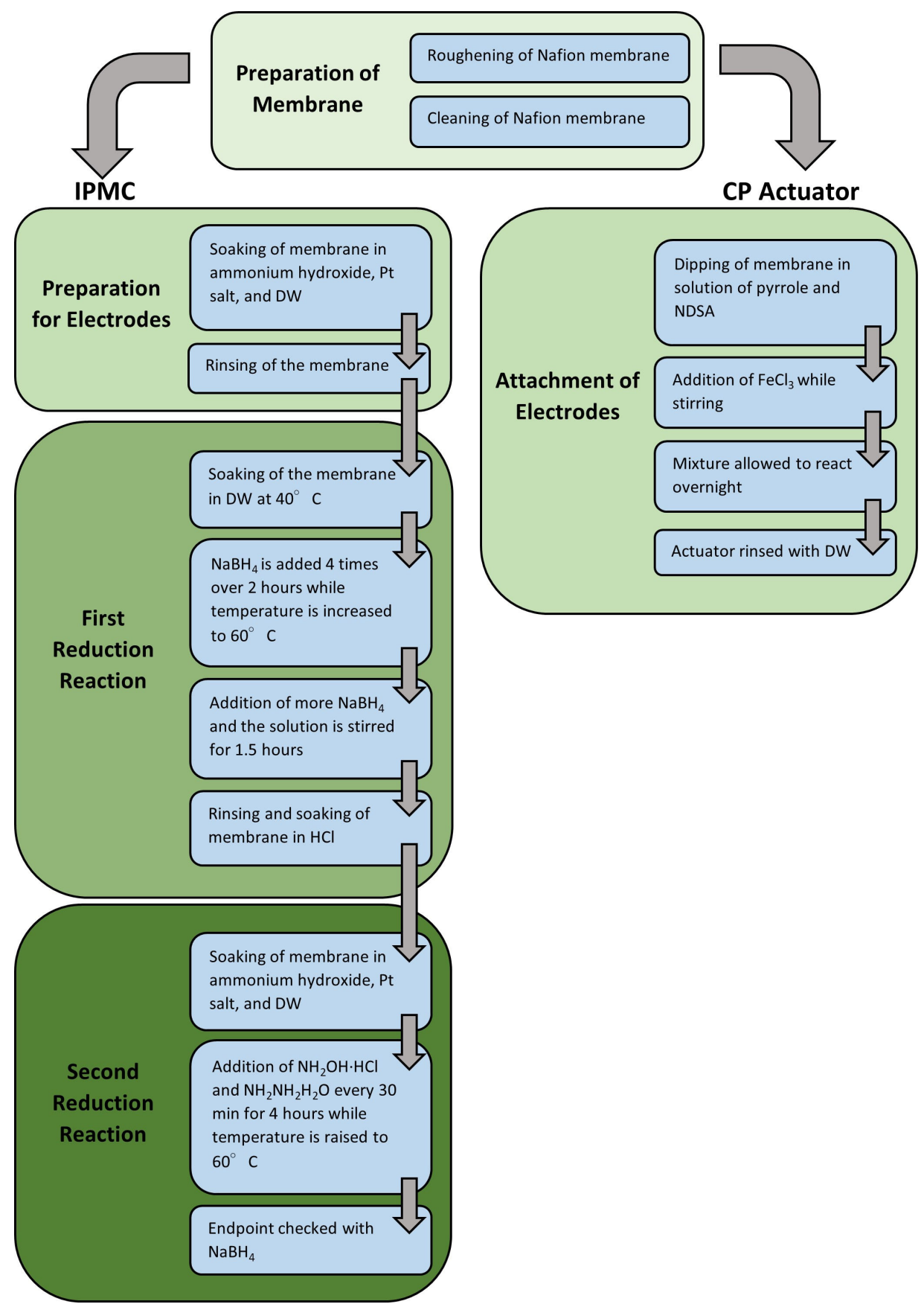

Figure 3. Synthesis steps of IPMC and CP actuator using Nafion ${ }^{\circledR}$ membrane.

\subsubsection{Ionic Polymer Gels (IPG)}

Conducting Polymers are often associated with ionic polymer gels since the same polymers used in CPs can be made into an ionic polymer gel. These gels consist of an ionic liquid in a solid matrix. They have gained attention since they do not include water, allowing them to function in the air better than other kinds of CPs. They are also similar in texture to biological muscles, making them potentially useful for biomedical purposes. Ionic polymer gel EAPs tend to follow a trilayer structure, with the gel forming the ionexchange membrane; and a conductive material, such as metals or conducting polymers, as the electrodes. Also, some gel actuators include a layer of activated carbon between the membrane and the electrode, forming a 5-layer structure, as shown below in Figure 4 [30]. 


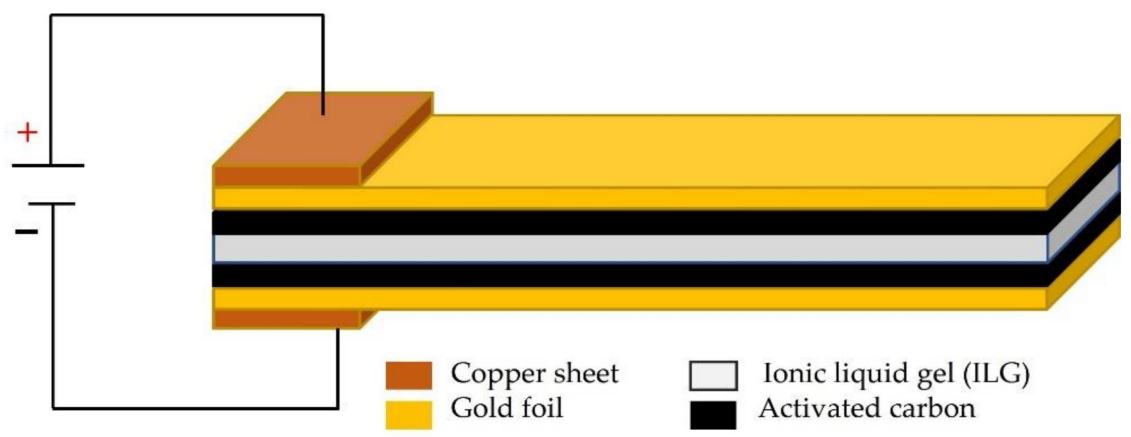

Figure 4. IPMC with a five-layer structure. Redrawn from [30].

One variant of ionic EAP gels could be developed with polymer-supported singlewalled carbon nanotubes (SWCNT) as the electrodes, which is called a "bucky gel" [31]. As shown in Figure 5, a transparent actuator could be made by using poly(dimethylsiloxane) combined with ionic liquid (PDMS/IL). PEDOT: PSS, which is the conducting polymer poly(3,4-ethylene dioxythiophene) (PEDOT) doped with poly(4-styrene sulfonate), forms the electrodes. The PDMS/IL gel electrolyte layer could be prepared by mixing PDMS and the ionic liquid of choice in $3 \mathrm{~mL}$ Dimethylacetamide (DMAc) by stirring for $3 \mathrm{~h}$. Then, $3 \mathrm{~mL}$ of this electrolyte solution is cast in a Teflon mold $(2.5 \mathrm{~cm} \times 2.5 \mathrm{~cm})$, and the solvent is allowed to evaporate. This is followed by complete removal of the solvent in a vacuum at $50{ }^{\circ} \mathrm{C}$. The PEDOT: PSS thin layer electrode could be spray coated onto the PDMS/IL gel electrolyte, followed again by complete removal of the solvent in vacuum at $50{ }^{\circ} \mathrm{C}$ [32].

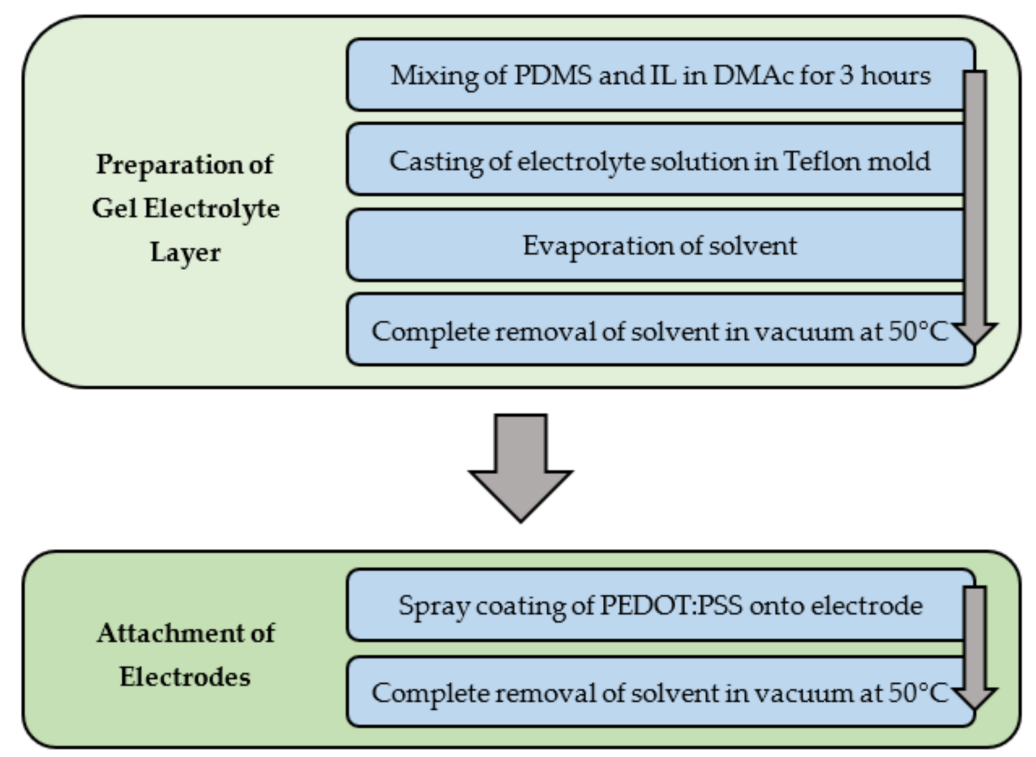

Figure 5. Synthesis of transparent ionic polymer gel EAP using PEDOT:PPS and IL of choice.

\subsubsection{Electrorheological Fluids (ERFs)}

Another type of ionic EAP is represented by electrorheological fluids (ERFs). ERFs most often consist of inorganic particles in suspension with a liquid, though there is also ongoing research on hybrid ERFs that include organic and inorganic materials [33]. These are defined for their ability to change viscosity in the presence of an electric field. Due to their ability to turn electric charge into mechanical energy, applications of ERFs primarily include valves, clutches, and robotic components. For these purposes, ERFs can be fabricated into various structures [33-35]. Polyaniline (PANI) is advantageous for such applications since it can be added to the matrix as nanoparticles (0D), as nanowires or nanotubes (1D), as nanosheets or nanobelts or films (2D), and as a hierarchical nanostructures 
(3D) [36-38]. Since there are two main parts of an ionic EAP made from ERFs, production could be divided into two main steps: (i) preparation of particles and (ii) dispersion of these particles into a fluid, which is commonly a silicon oil. Also, an intermediate step is needed to collect and clean the nanoparticles before dispersion. Figure 6 shows the preparation of an ERF based on PANI and $\mathrm{TiO}_{2}$.

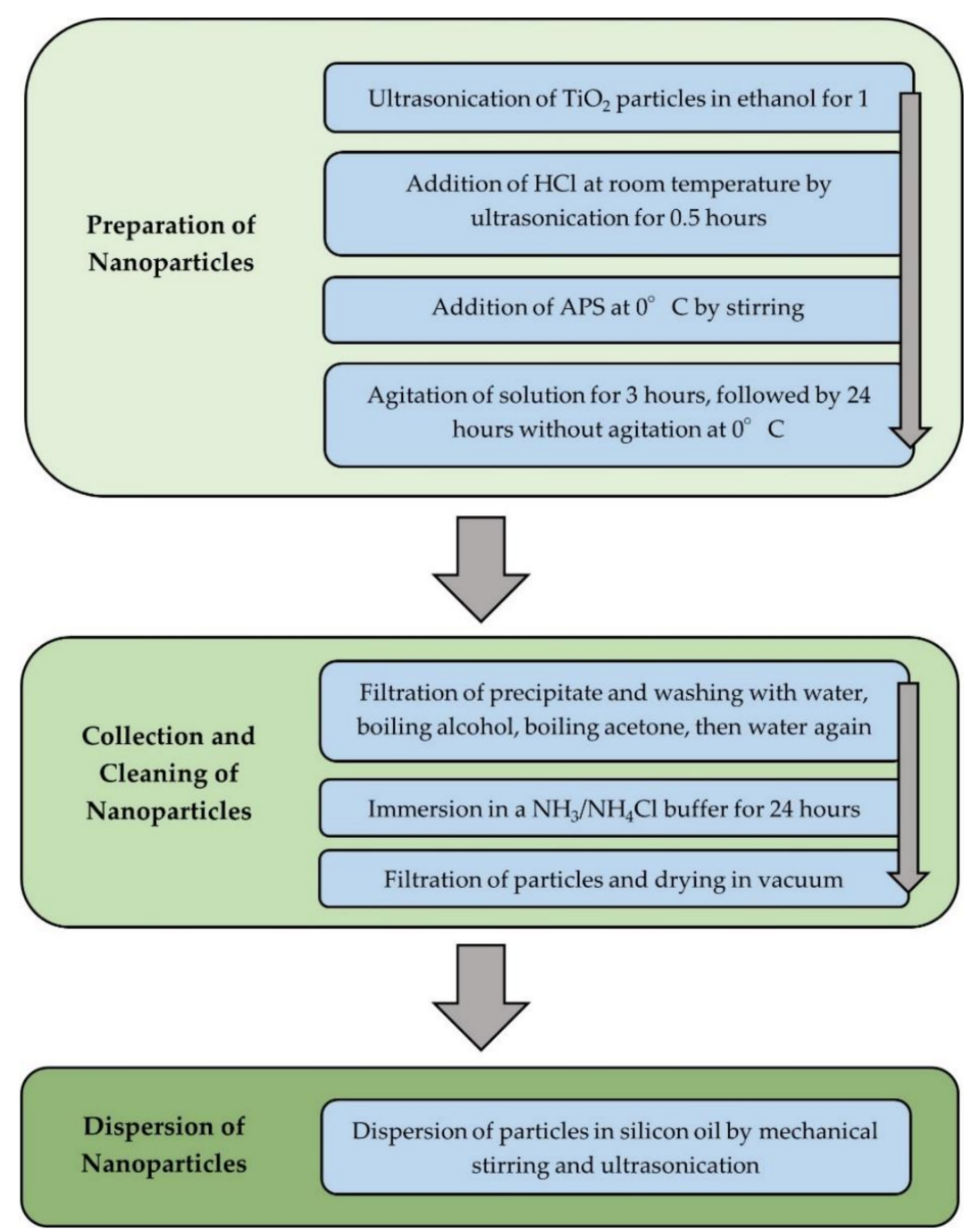

Figure 6. Synthesis of ERF made from PANI and $\mathrm{TiO}_{2}$ dispersed in silicone oil.

Commercially available anatase $\mathrm{TiO}_{2}$ nanoparticles are well-dispersed in ethanol by ultrasonication for $1 \mathrm{~h}$, followed by the addition of concentrated $\mathrm{HCl}$ at room temperature with continuous ultrasonication for $0.5 \mathrm{~h}$. [36]. After $12 \mathrm{~h}$ at room temperature, distilled aniline was added through ultrasonication over $0.5 \mathrm{~h}$. The mixture was maintained at $0{ }^{\circ} \mathrm{C}$ with a cooler. A solution of ammonium persulfate (APS) in water was dropped into the mixture and rapidly stirred. After being continuously agitated for $3 \mathrm{~h}$ under $0{ }^{\circ} \mathrm{C}$, the mixture was then left for another $24 \mathrm{~h}$ at $0{ }^{\circ} \mathrm{C}$. The precipitate is filtered and washed with water, boiling alcohol, boiling acetone, and then water again. Then, the particles are immersed in an $\mathrm{NH}_{3} / \mathrm{NH}_{4} \mathrm{Cl}$ buffer solution for $24 \mathrm{~h}$. After being filtered and dried in a vacuum, the $2 \mathrm{D}$ structured $\mathrm{PANI} / \mathrm{TiO}_{2}$ nanosheets are obtained. The nanosheets are blue-brown and appear as particles due to their small diameter [36]. The nanosheets are then dispersed in silicon oil with a mechanical stirrer and ultrasonicated to create the ERF [36]. Figure 6 shows the three main steps of the production process. Consistent with the large variety of ionic EAPs, the steps taken in the synthesis of ionic EAPs vary widely 
depending on the materials used and their intended function. There are some considerable properties to determine the feasibility of ionic EAPs in certain applications. For example, the amount of voltage required to obtain a certain magnitude and speed of displacement. There has been much investigation into optimizing these parameters through changing the composition or production methods of ionic EAPs. For that purpose, the types of IL in the ionic EAP could change the charging time, which is the amount of time the ionic EAP takes to reach full displacement once voltage is applied [39-41]. The type of IL could also change bending strain and velocity [39-41]. Also, the trilayer actuator structure that is common in many ionic EAPs can be modified into two-layer or five-layer structures depending on the materials involved. The wide array of potential production techniques and materials in ionic EAPs necessitates further research.

\subsection{Electronic and Other Types of EAPs}

Electronic electroactive polymers have received significant research attention in the last few decades. In contrast with ionic EAPs, Electronic EAPs do not require any electrolyte medium or ion migration [42]. Therefore, the field of electronic EAPs is rapidly developing with the increased interest in lightweight materials that are biocompatible and simple to manufacture [43]. So far, different kinds of electronic EAPs have been developed for numerous applications. Dielectric, electrostrictive graft, electrostrictive paper, electro-viscoelastic, ferroelectric, and liquid crystal are some notable electric EAPs, widely discussed in the literature [43-45].

\subsubsection{Dielectric EAPs}

Dielectric EAPs exhibit actuation using the electrostatic forces between two electrodes. They are similar to a capacitor that can change its capacitance in response to an applied voltage. They are capable of very high strain, and due to the applied electric field, they get compressed in thickness while their area gets expanded.

Aramoni et al. [44] addressed a production method for dielectric elastomer actuators (DEAs) using the spray coating technique. This was a four-step process, as shown in Figure 7. First, a low viscosity liquid was formed from a mixture of Silastic 3481 silicone base and a curing agent at a 5:1 ratio [44]. This liquid was then sprayed onto the edge of a disk rotating at a constant velocity [44]. After the solvent evaporated, in the second step, the electrode was lightly brushed on in a similar fashion [44]. In the next step, the mixture was sprayed on the electrode film, while the offset areas were shielded from the spray. Finally, the actuator was removed from the wheel, and a voltage was supplied to carry forward the operation of the DEA-based actuator. The last image (d) also shows the typical circuit of electronic EAP. BarCohen et al. [43] also produced one type of dielectric EAP-based artificial muscle using a novel silicone-based fabrication method. This production method for DEAs is especially well suited for low volume production due to its simple techniques and low production costs [43].

\subsubsection{Electrostrictive (Graft and Paper)}

Electrostriction is the term that commonly denotes a quadratic coupling between strain and electric polarization, and it is present in all-dielectric insulators. There is currently interest in developing mesoscale compressors that could be used in computers. The choice of the actuator technology is the most important consideration to develop a mesoscale compressor [46]. Traditional approaches to actuation on this so-called mesoscale level include electrostatic, piezoelectric, and thermomechanical [46]. Depending on the application, these traditional actuators might not offer the correct combination of force and movement [46]. Alternatively, it is possible to use the electrostrictive capabilities of polymers to produce an actuator with superior qualities [45]. Electrostriction takes place when electric dipoles within the polymer are pushed or pulled by the applied electric field, resulting in deformation $[45,47]$. Electrostrictive polymers (EPs) have been shown to 
produce up to 20 times the effective actuation pressure as a traditional electrostatic material when applying the same electric field [45].

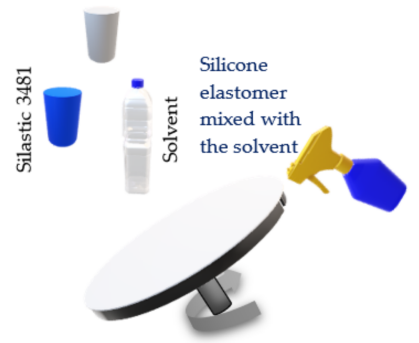

(a) Elastomer film

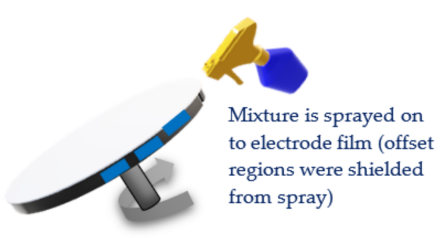

(c) Additional layer sprayed directly on top of the previous layers

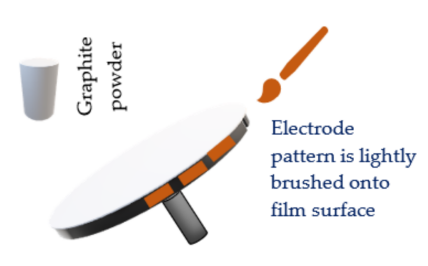

(b) Brushing Electrode

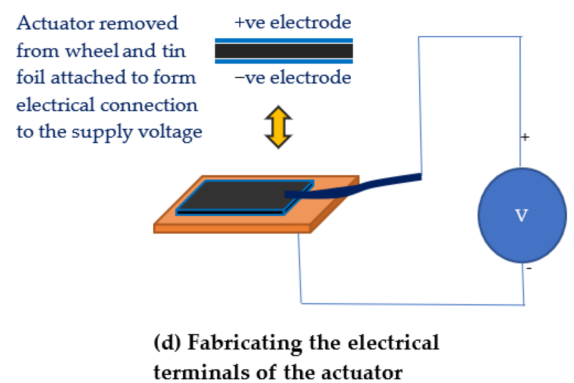

Figure 7. The fabrication process of a multilayer DEA using spray technique. Drawn based on $[43,44]$.

A requirement to producing an EP is a thin and uniform dielectric film [45]. These films can be fabricated through a number of techniques such as spin coating, casting, or dipping [45]. Electrode materials may also vary from powdered graphite, ionically conductive polymers, and carbon blacks and fibrils in polymeric binders [45]. Actuator prototypes have been successfully synthesized in configurations such as stretched films, stacks, rolls, tubes, and unimorphs [45]. Most processes start with an uncured polymer being dispersed in a solvent or liquid carrier to lessen the viscosity [45]. The purity of the polymer is also an important metric, and it was found that centrifuging commercial polymers may significantly benefit the performance of the final actuator [45]. One fluorosilicone (Dow Corning RTV730) had an increase in maximum strain from 14 to $28 \%$ using centrifuging [45].

Fukushima et al. [46] used Dow Corning Sylgard Silicones (182 and 184), which are highly viscous $(3.9 \mathrm{~kg} / \mathrm{ms})$ [46]. The silicone consists of a base and a curing agent, supplied separately, which were mixed in a 10:1 ratio [46]. It takes $30 \mathrm{~min}$ to begin the curing process while air bubbles produced during mixing can escape [46]. While a vacuum chamber was not used in this paper, they are known to be useful for the thorough removal of air bubbles in a liquid. Despite the manufacturer's recommendation of using glass as the curing surface, Teflon was used to improve the safe release of the polymer since the thickness will be below $100 \mu \mathrm{m}$ [45]. Releasing agents may hinder the curing of the films, so none were used [45]. The curing of the films was completed over the course of $24 \mathrm{~h}$ between temperatures of 100 and $150{ }^{\circ} \mathrm{C}$ [45].

Electrodes are needed to apply voltages to the polymer films. The electrode choice aims to minimize any mechanical interference. To allow the free expansion and contraction of the film, the electrode must be significantly thinner than the film and be designed in a structurally compliant way [45].

\subsubsection{Electro-Viscoelastic}

It is common for elastomer materials to be sensitive to loading strain rates, showing a mechanical behavior with strong time dependence [48]. A material considered to be electroviscoelastic is a nearly incompressible PU elastomer that displays rubbery properties and is capable of large deformations [48]. Achieving these characteristics through production has many complexities that are currently being modelled through the use of computer 
simulations [48-50]. A drawback of dielectric elastomers is the failure of the components arising from different mechanisms. One of these mechanisms is called pull-in instability, which can only occur if the actuator is voltage driven [50]. Typically, all edges of EAPs are constrained during testing, leading to wrinkled regions, which may distort or snap the electrical conductors present [50]. Pull-in instability will cause the material to lose its ability to compensate the applied electric energy with proportional elastic deformation and will often result in the collapse of the material [50]. A proposed solution to this pull-in instability is the use of electro-viscoelastic materials and will require further physical and computational analysis [48-50].

\subsubsection{Ferroelectric}

Ferroelectric EAPs are useful in a wide array of applications such as electro-mechanical actuators [51], ultrahigh-energy density capacitors [52], and on-chip cooling devices [53]. In this section, the production of nano-imprinted ferroelectric polymers for the purpose of high density and low energy data storage will be reviewed.

A material that shows promise as a thin-film and non-volatile memory is vinylidene fluoride-trifluoro ethylene copolymers, i.e., $\mathrm{P}(\mathrm{VDF}-\mathrm{TrFE}) \mathrm{s}$ [54]. This material has excellent solubility, processibility, and flexibility which are important parameters to consider when planning synthesizing a useful memory storage device [54]. P(VDF-TrFE)-based polymers require a relatively large electric field, about an order of magnitude higher than an inorganic ferroelectrics, to drive changes in the polarization of the crystals during writing and reading operations in memory devices [54]. In order to produce a compatible material, it was required to reduce the film thickness to the sub-micrometer scale [54]. Recent research suggests that ferroelectric properties will still be usable in copolymer films as thin as a few molecular monolayers [55].

Chen et al. [54] used a nanscale imprinting lithography, which decreased the size of the data-storage elements. This lithography technique also served to isolate the individual ferroelectric memory units [54]. To achieve this separation, anodic aluminum oxide $(\mathrm{AAO})$ was used as a template. AAO is easily tunable during fabrication and contains a honeycomb-like structure, which is a highly ordered shape with nanometer-scale pores [54]. Once the disposable AAO mold has been set into position on a substrate, the standard thermal imprinting lithographic technique deposits the $\mathrm{P}(\mathrm{VDF}-\mathrm{TrFE})$ into the pores of the AOO, as shown in Figures 8 and 9.

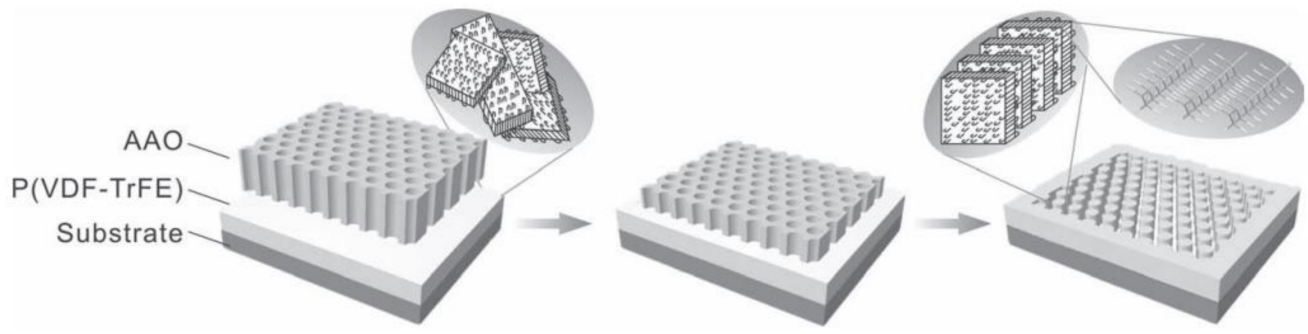

Figure 8. Procedure of nano-imprinting $\mathrm{P}(\mathrm{VDF}-\mathrm{TrFE})$ using AAO (Reproduced with permission from [54]. Copyright Wiley and sons, 2013).

It is also possible to pursue different applications with the $\mathrm{P}(\mathrm{VDF}-\mathrm{TrFE})$ copolymer by converting it from a normal ferroelecric to a relaxor ferroelectric. Relaxor ferroelectrics have the unique characteristic of heterogeneous polar states at the nanoscale and they exhibit impressive electromechanical properties [56]. Bauer et al. synthesized relaxor ferroelectrics with $\mathrm{P}(\mathrm{VDF}-\mathrm{TrFE}-\mathrm{CFE})$ and $\mathrm{P}$ (VDF-TrFE- CTFE) by introducing defects to the P(VDF-TrFE) copolymer [57]. There, the defects came in the form of 1, 1-chlorofluoroethylene (CFE) or chlorotrifluoroethylene (CTFE) monomers. In such cases, the monomer is randomly introduced into the polymer chain; this helps to obtain a relaxor ferroelectric, from the normal ferroelectric phase $[57,58]$. 

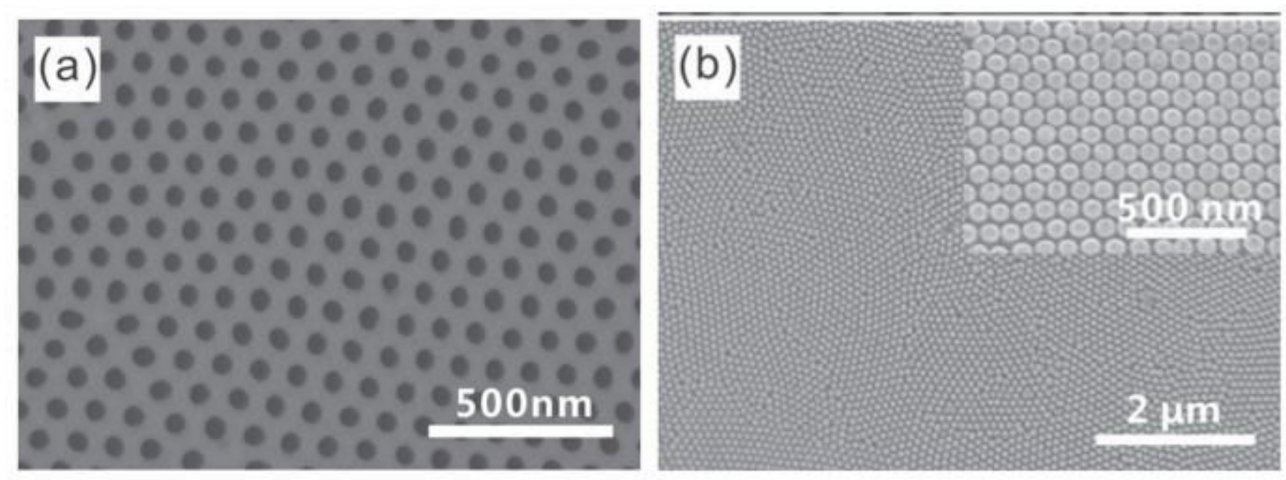

Figure 9. $\mathrm{P}(\mathrm{VDF}-\mathrm{TrFE})$ nanodot arrays at different scales: (a) $500 \mathrm{~nm}$, (b) $2 \mu \mathrm{m}$; taken with SEM (Reproduced with permission from [54]. Copyright Wiley and sons, 2013).

\subsubsection{Other EAPs}

There are many other subcategories of EAPs, and as technology in this field continues to progress, it is harder to place each material in a category based on its application and properties. Moreover, new advancements use the basic concept of the ionic and electric EAPs in order to adapt to a specific need rather than large-scale manufacturing. These specialized materials may contain certain aspects of both ionic and electronic EAPs; however, they can behave like an entirely different material. As we are focusing mostly on ionic EAPs, we will restrict ourselves from the detailed discussion of other types. However, more details on the development and functionalities of electronic and other types of EAPs could be found elsewhere [48,59-64].

\section{Properties of EAPs}

EAPs are a robust family of materials with versatile mechanical, electrical, electromechanical, and tribological properties. Each of these properties plays a significant role in serving the intended purpose in actuator, coating, or soft electronics. By combining general polymer attributes and electro-mechanical properties, EAPs have become a material that attracts the attention of scientists and engineers [65]. In the following subsections, the mechanical, electroactive, and tribological properties of ionic EAPs will be covered.

\subsection{Properties of Ionic EAPs}

Mechanical properties are important physical properties that a material exhibits against an applied force. Modulus of elasticity, fatigue limit, tensile strength, flexibility, and hardness are some of the mechanical properties of EAPs. These properties modulate the bending capability when the EAP is used in actuators.

Among ionic EAPs, ionic polymer-metal composites (IPMCs) can produce soft actuators. IPMCs have large bending capabilities and easy processing ability [66]. Large deformation and bending could be generated by applying a low voltage between 0.5 and $3.0 \mathrm{~V}$ in water [67]. There are investigations to exploit the bending motion of IPMCs, and many researchers tried various precious metals as electrodes, such as $\mathrm{Au}, \mathrm{Pt}, \mathrm{Pd}, \mathrm{Ag}$, along with transition metals such as $\mathrm{Ni}$, Fe on Nafion ${ }^{\mathrm{TM}}$ films [66]. One of the studies led by Park et al. [55] compared the mechanical properties of various IPMCs with different electrode types ( $\mathrm{Pt}, \mathrm{Au}, \mathrm{Pd}$, and IL-Pt: Platinum electroded ionic liquid). Using a universal testing machine in a tensile mode and dynamic mechanical analysis (DMA) in a shear mode, it was found that Au-IPMCs have the highest tensile strength (56 MPa) and modulus of elasticity (602 MPa) in dried conditions (Table 1). In another study, Xu et al. [68] studied Ag-IPMC and the impact of water content on the elastic modulus and Poisson's ratio of the Ag-IMPC material. The result shows that the elastic modulus of the newly produced Ag-IPMC is less than $23 \mathrm{MPa}$, and the elastic modulus increased negatively as the moisture content decreased. The elastic modulus achieved $139 \mathrm{MPa}$ when the moisture content 
dropped to $1.09 \%$ [68]. On the other hand, Poisson's ratio increased from 0.42 to 0.49 with an increase of water content from $0 \%$ to $15 \%$.

Table 1. The tensile properties of substituted polyacetylenes.

\begin{tabular}{|c|c|c|c|c|c|c|}
\hline & Material & $\begin{array}{l}\text { Young's Modulus } \\
\text { [GPa] }\end{array}$ & $\begin{array}{l}\text { Stress } \\
{[\mathrm{MPa}]}\end{array}$ & $\begin{array}{c}\text { Strain } \\
{[\%]}\end{array}$ & $\begin{array}{c}\text { Tensile } \\
\text { Strength } \\
\text { [MPa] }\end{array}$ & Ref \\
\hline 1 & $\begin{array}{l}\text { Polypyrrole } \\
\text { (PPy) }\end{array}$ & $5-60$ & 30 & 14 & - & {$[67,69-71]$} \\
\hline 2 & $\begin{array}{l}\text { Polyaniline } \\
\text { (PANi) }\end{array}$ & - & - & - & 12.6 & {$[67,72]$} \\
\hline 3 & $\begin{array}{c}\text { Poly } \\
\text { (3,4-ethylenedioxythiophene) } \\
\text { (PEDOT) }\end{array}$ & $1.8-2.6$ & 17 & 1 & - & {$[67,73]$} \\
\hline 4 & Polythiophene & $3-7$ & - & - & - & {$[74,75]$} \\
\hline \multirow[t]{2}{*}{5} & Polyacetylene & $40-50$ & - & - & $900-2100$ & {$[76,77]$} \\
\hline & Silicone-made actuators & & & 380 & & {$[78]$} \\
\hline 6 & Polyphenylen viylene (PPV) & $\begin{array}{c}2.3-37 \\
\text { (in the machine } \\
\text { direction) } \\
\text { 2.3-0.5 (in the } \\
\text { transverse direction) }\end{array}$ & - & - & - & [79] \\
\hline 7 & $\begin{array}{c}\text { Piezoelectric P(VDF-TrFE) } \\
\text { copolymer }\end{array}$ & 4 & 6 & 0.15 & - & [80] \\
\hline 8 & Electrostrictive P(VDF-TrFE) & 0.4 & 20 & 5 & - & [80] \\
\hline 9 & $\begin{array}{c}\text { Nylon11 } \\
\text { (polyamide 11) }\end{array}$ & 1.2 & - & - & $43.7 \pm 2.5$ & [81] \\
\hline 10 & Polyurea & - & - & - & $93.1 \pm 5$ & {$[82,83]$} \\
\hline 11 & PVDF & 2.5 & & & $35-50$ & {$[84,85]$} \\
\hline 12 & Nafion (dried) & 0.1316 & 30 & - & 29.3 & {$[66]$} \\
\hline 13 & Nafion (Hydrated) & 0.030 .4 & 17 & & 16.5 & [66] \\
\hline 14 & Pt IPMC (dried) & 0.1143 & 28 & - & 28.0 & {$[66]$} \\
\hline 15 & Pt IPMC (Hydrated) & 0.0412 & 11 & & 11.2 & [66] \\
\hline 16 & Au IPMC (dried) & 0.6026 & 55 & - & 55.7 & [66] \\
\hline 17 & Au IPMC (Hydrated)d & 0.0709 & 21 & & 20.8 & {$[66]$} \\
\hline 18 & Pd IPMC (dried) & 0.1416 & 30 & - & 30.1 & [66] \\
\hline 19 & Pd IPMC (Hydrated) & 0.0304 & 15 & & 14.7 & [66] \\
\hline 20 & IL-Pt IPMC & 0.0206 & 13 & - & 11.2 & {$[66]$} \\
\hline 21 & Ag IPMC & $0.023-0.139$ & 17 & - & - & [68] \\
\hline
\end{tabular}

Polypyrrole (PPy), Polyaniline (PANi), Poly (3,4-ethylenedioxythiophene) (PEDOT), Polythiophene, Polyacetylene, and Polyphenylen vinylene (PPV) in Table 1 are different conductive polymers. Among them, PPy and PANi have been most commonly studied. The strain rate of PPy is between 2-30\% under the voltage range from 1 to $3 \mathrm{~V}$, and its high stresses can reach up to $30 \mathrm{MPa}$ [67]. Since PANi is prepared by oxidative polymerization in acidic aqueous solutions, it is easily fabricated into films and fibers that can be used in the actuators. Compared to PPy and PANi, the toughness of the PEDOT films is much lower. However, PEDOT has high stability in electrochemical reactions [67]. 


\subsection{Properties of Electronic EAPS}

In the performance of EAPs, electric properties play a significant role. These properties include, but are not limited to, electrostriction, dielectric constant, capacitance, impedance, and electrical conductivity [86]. Each of these properties has impact on the EAP's mechanical and chemical properties. The impacts may vary across each respective EAP, but since EAPs are a family of polymers, there are a lot of similarities within the family.

Compared to ionic EAPs $(<10 \mathrm{~V})$, electronic EAPs are driven by larger electric fields ( $>100 \mathrm{MV} / \mathrm{m}$ ) to achieve linear deformation between the 4 to 360\% range [87]. Polyvinylidene fluoride (PVDF) is one of the most common EAPs with ferroelectric behavior [67]. PVDF has high stiffness, mechanical strength, toughness and creep and abrasion resistance, good chemical resistance, high dielectric strength, chemical inertness, low flammability, and low moisture absorption capabilities [85]. Dielectric elastomers (DEs) are capable of large strains and change their capacitance when a voltage is applied by compressing the thickness of the polymer and expanding its cross-section [88]. This type of EAPs typically requires a large voltage to generate a high electric field, but it consumes very little power [88]. PVDF, PVDF's copolymer of trifluoroethylene (PVDF-TrFE), nylon-11 and polyuria are considered piezoelectric polymers [89]. PVDF and its copolymers constitute most polymer-based piezoelectric generators [90]. Piezoelectric polymers have a lower piezoelectric strain constant than ceramic materials [91]. However, piezoelectric polymers could help to develop much better sensors than ceramics due to higher piezoelectric stress constant [91]. Piezoelectric polymeric sensors and actuators have the advantage of processing flexibility being lightweight, tough, and amenable to be easily cut and formed into complex shapes [91].

Electrostriction is a phenomenon that can occur in EAPs when they undergo electrically induced strain. Tagarielli et al. [8] studied the mechanical response of VHB49, a popular dielectric EAP material produced by $3 \mathrm{M}$. They measured the sensitivity of the mechanical response to the imposed strain rate by tensile and compression tests and relaxation experiments under constant strain rate [8]. It is well known that when an electric potential difference is applied between two points of a dielectric material via conductive electrodes, an electrostatic force acts on the material. This electrostatic force can introduce a remarkable strain in the material known as the electrostriction phenomenon [8]. Tagarielli et al. [8] used conductive grease as the electrode material and observed hyperelastic and highly viscous material response, resulting in high strain rate sensitivity and a long relaxation time [8]. Also, they studied the dielectric constant, which refers to a material's capability to store electrical energy. The typical dielectric constant of VHB materials with gold electrodes is between 4.05-4.72, as reported in the literature [92-95]. Tagarielli et al. [8] concluded that the dielectric constant decreases as the tensile pre-strain increases. If an electroactive polymer is to be used in a strong actuator, then a high dielectric constant is necessary [96].

In another study, Cong et al. [92] studied the effect of pre-stretching on the dielectric constant of two dielectric EAPs (silicone and acrylic elastomer) by varying the surface expansion ratio from 1 to 16 and from 1 to 2 for acrylic (VHB 4910) and silicone accordingly. It was found that the dielectric constant decreased with an increase of tensile pre-stretch. A similar phenomenon was observed in other literature and summarized in Table 2. In Table $2, \lambda_{1}$ and $\lambda_{2}$ are axial and transverse stresses accordingly. 
Table 2. Effects of pre-stretch on the dielectric constant, observed in the literature (Reproduced with permission from [92], Copyright IOP Publishing Ltd., 2012).

\begin{tabular}{|c|c|c|c|c|c|c|c|c|c|}
\hline & Cong [92] & Jean-Mistral [92] & Cong [92] & Cong [92] & Li [97] & Choi [98] & McKay [99] & Kofod [100] & Wissler [94] \\
\hline Polymer & VHB 4910 & VHB 4910 & VHB 4910 & VHB 4910 & VHB 4910 & VHB 4910 & VHB 4905 & VHB 4910 & VHB 4910 \\
\hline Electrode & $\begin{array}{l}\text { Acrylic } \\
\text { carbon }\end{array}$ & Silver grease & Silver grease & $\begin{array}{l}\text { Carbon } \\
\text { grease }\end{array}$ & $\begin{array}{l}\text { Carbon } \\
\text { grease }\end{array}$ & $\begin{array}{l}\text { Carbon } \\
\text { grease }\end{array}$ & $\begin{array}{l}\text { Carbon } \\
\text { grease }\end{array}$ & $\begin{array}{c}\text { Carbon } \\
\text { black + } \\
\text { Metal }\end{array}$ & Gold \\
\hline $\begin{array}{c}\text { Sample } \\
\text { diameter }(\mathrm{m})\end{array}$ & 0.016 & 0.016 & 0.016 & 0.016 & 0.010 & 0.010 & 0.030 & 0.030 & 0.025 \\
\hline$\lambda_{1} \lambda_{2}=1$ & 4.55 & 5.40 & 5.28 & 5.27 & 4.50 & 4.30 & 4.59 & 4.70 & 4.68 \\
\hline$\lambda_{1} \lambda_{2}=9$ & 3.55 & 4.95 & 4.20 & 4.25 & 3.25 & 2.25 & 4.00 & 4.55 & 3.71 \\
\hline$\lambda_{1} \lambda_{2}=16$ & 3.50 & 4.60 & 4.25 & 4.30 & 1.75 & 2.50 & 3.75 & 4.50 & 3.34 \\
\hline
\end{tabular}

\subsection{Properties of Conjugated EAPs}

Conjugated polymers are considered a potential material for fabricating soft actuators that can operate indefinitely at low voltage in the air [101]. Although many examples of conjugated polymer actuators have complex structures, a dry actuator can be easily manufactured by layer-by-layer casting with "Bucky Gel," which is a gelatinous room temperature ionic liquid containing single-walled carbon nanotubes (SWNTs) [101]. Carbon nanotubes (CNTs) are considered the strongest and stiffest materials. Reports on microscopic studies have predicted that the tensile strength of single-walled CNTs (SWCNTs) is $94-126 \mathrm{GPa}$, and Young's modulus of SWCNTs is around $0.915 \mathrm{TPa}[102,103]$. It is also observed through atomic force microscope (AFM) that the tensile strength of an individual multi-walled CNT (MWCNT), which is attached between AFM tips is $63 \mathrm{GPa}$, and its Young's modulus is 270-950 GPa [104]. However, the very first macroscopic study on CNT was done by Kim et al. [105] recently, where the average tensile strength and Young's modulus of the millimeter long CNTs were determined to be $0.85 \mathrm{GPa}$ and $34.65 \mathrm{GPa}$. This explains the reason for MWCNT conjugated EAPs low mechanical properties. Moreover, CNTs could not be advantageously introduced into the nanocomposites due to their poor dispersion and waviness [105,106]. More research in this field is ongoing to improve the overall properties of conjugated EAPs.

\section{Recent Advancements in the Applications of Electroactive Polymers}

EAPs are notable for their ability to turn electrical energy into mechanical energy. In particular, EAPs are widely investigated for actuators. EAPs can be beneficial in circumstances where hard mechanical parts may be undesirable. Additionally, EAP actuators are a single component rather than a series of parts that may rub and produce wear. EAPs can operate with minimal noise, and their use could dramatically reduce wear and friction compared to traditional actuators $[107,108]$. Furthermore, their flexible nature helps them to alter their properties according to the situation for which they are needed [109]. These properties make EAP actuators useful for multiple applications where traditional actuators are not optimal. Also, in recent years, EAPs-based coating has become a viable option for improving product performance. There are a variety of advantages that becomes available by coating a substrate material with EAPs. Those advantages include: increasing electrochemical capacitance, reducing friction, wear, corrosion protection, reducing electric resistance, biomedical applications, and stabilization of oxide surfaces [110]. Therefore, EAPs have been successfully used in fields such as engineering and medicine to make numerous devices. Some of the interesting applications of EAPs are highlighted here.

\section{(a) Robotic Actuators:}

In the field of robotics, soft robots using EAPs have significant potential. Soft actuators are able to deform while still being functional, making them safe for interaction with humans. Furthermore, their flexibility and adaptability allow for novel robotic motion, such as a snake-shaped robot capable of serpentine motion [111]. Their flexibility also allows for the development of nuanced structures, such as a simulated human fingertip. The 
potential for most EAPs to be made into actuation devices allows for virtually all EAPs to be used in robotics according to specific requirements. However, a few types stand out as the most widely applicable. Dielectric elastomers (DEAs) could be particularly useful in some robotic applications due to their large deformations, light weight, easy production, and adaptability [112]. CP actuators can also be useful, particularly in biomedical applications, because they are typically bio-compatible and can be manufactured at the micro and nano scales [113]. Various other types of EAPs are useful depending on the exact circumstances that the actuator is intended to be used.

(b) Synthetic muscles:

Synthetic muscles, either for use as prosthetics or robotic components, represent another potential application for EAP actuators. The characteristics of EAPs, such as their large bending strain and similarity to natural muscles, would make them useful as synthetic muscles [114]. Furthermore, EAPs generally have inaudible actuation. This makes them viable for prosthetics since they would not audibly disrupt the user or others. Dielectric EAPs, in particular, have been investigated for their potential as synthetic muscles due to their quick response time, durability, and noiselessness [115]. Some EAP actuators have even proven useful in the field of acoustic engineering for sound dampening. EAP actuators have been used for devices, such as noise-cancelling headphones, transducers, and resonators [116-118]. However, the high activation voltage of electrical EAP actuators may be dangerous for users. Another challenge is handling the dielectric breakdown, which is not desirable in a synthetic muscle $[119,120]$. Some types of ionic EAPs may also be used to create synthetic muscles, as their bending deformation can be used to obtain linear motion with the appropriate techniques [121]. Regardless of the type of EAP that is used as synthetic muscles, tribological considerations are significant due to the damage and pain that friction can cause in the human body [122]. Also, electroactive polymer coating was found useful for developing flexible artificial muscles. Ebadi et al. [123] applied EAP coating to polyurethane nanofibers, and achieved an angular displacement between $48-225^{\circ}$. This illustrates a clear benefit, especially when considering flexible bodies as muscles.

\section{(c) Underwater applications:}

For underwater applications, EAP actuators can be used for noise less propulsion. Sound pollution by traditional propulsion methods, such as motorboats, has been demonstrated to have several detrimental effects on marine life [124]. EAP actuators have the potential to be a low-noise alternative. Additionally, EAP actuators can be small and able to mimic the movement of aquatic animals, which is useful in oceanographic engineering [125]. Ionic EAPs are particularly useful underwater since many types function well in aqueous solutions [126]. IPMCs, for instance, are highly deformable even at low voltages, soft, flexible, and especially advantageous underwater since they would not encounter the problem of dehydration that occurs when an IPMC is in the open air. It has been demonstrated that the stacking of IPMCs may be effective at ensuring greater actuation underwater than a single IPMC [126]. A turtle-like robot with wireless charging was made for underwater use, demonstrating the wide range of potential for the use of IPMCs underwater [125]. Ionic gel actuators and conducting polymer actuators have similar advantages in an underwater environment, although more research has been done on IPMCs [113,127].

(d) Wearable electronics:

Wearable electronics is another sector in which EAP actuators are widely used. Since they are flexible, they can adapt to the shapes of human body parts. Additionally, they can be fabricated as very small devices, so that they can be used for nuanced applications. For instance, Ig Mo Koo et al. developed a tactile display for a human fingertip that consists of a series of tactile simulators made with dielectric elastomers [13]. It is even possible to create a fabric with EAPs that has the potential to change its density based on the activity for which it is needed [128]. Wearable EAPs could also be harnessed to harvest mechanical 
energy because they generate an electric charge when they are deformed. Electronic EAPs are the most common type of EAPs for these applications since they are easier to operate in the open air compared to ionic EAPs. However, ionic EAPs have the potential to be safer for human use because of their lower activation voltage. Polyvinylidene fluoride (PVDF) is a type of electrical EAPs that has gained attention for wearable technology due to its superior properties [12].

\section{(e) Energy storage systems:}

EAP coatings are commonly made up of conductive polymers. In terms of actuation, when a coating is applied, an exchange of ions and solvent molecules between the coating and the polymer structure takes place, and when an electrical current is produced, it leads to chemical reactions [129]. One application of EAP-based coating is increasing the electrochemical capacitance. This can be achieved by depositing the polymer coating onto a material, such as graphite foil, and then proceeding to drying and weighing the material [129]. This coating can modify the electrodes in the electrochemical energy storage systems [129].

\section{(f) Drug delivery:}

A recent development in EAP-based coatings was observed in the field of drug delivery into the bloodstream. Polymer-based drugs can deliver necessary doses to patients with a controlled release. This is possible by electrical stimulation of the polymer coating, which in turn will allow for a proper amount of the drug to be released at specific times [130]. This process requires a very low amount of power and operates at a low voltage to make it safer for humans. Hardy et al. [131] studied oligoaniline-based electroactive blocks linked to polycaprolactone block or polyethylene glycol for drug delivery application. There, the EAP was able to deliver the anti-inflammatory drug- dexamethasone phosphate. These electroactive polymers are biodegradable and maintain safe conditions for humans. This process is beneficial since it can release the drug at more advantageous times to avoid potentially harmful side effects [130]. Current progress shows tremendous potential and more research is ongoing to ensure reliability of such applications [132].

\section{(g) Shape memory polymers:}

Shape memory effect refers to the phenomenon, by which a material recovers its original shape and size due to heating above a certain transformation temperature. Recent studies showed that electroactive shape memory polymers (EASMPs) are suitable through remotely controllable actuators where direct heat application is not convenient $[133,134]$. For example, Li et al. [133] investigated a new electroactive shape memory, polyimide (EASMPI) in 2019. This material has both characteristics of electroactive and shape memory effect [133]. EASMPI was produced by incorporating ground carbon fibers (GCFs) into the polyimide matrix [133]. EASMPI offers a glass transition temperature of $302{ }^{\circ} \mathrm{C}$ which is higher than other EASMPs, reported in literature [133]. Before that, the maximum glass transition temperature of EAPs was reported as $150{ }^{\circ} \mathrm{C}$ or less $[133,135,136]$. A high glass transition temperature is helpful for EAPs because it offers them a higher threshold to transfer shape. In other words, it helps the EAPs in offering shape memory applications at higher temperatures. In the case of EASMPI, the shape recovery was activated by a voltage of $15.87 \mathrm{~V}$ [133]. This voltage was converted into thermal energy, which raised the temperature of the EASMPI to above the shape transition temperature, causing shape recovery [133]. The recovery stress of EASMPI was $40.1 \mathrm{MPa}$ [133] and reflects a good ability to exert mechanical work.

(h) Dielectric elastomeric generator:

With an ever-increasing demand for electrical energy in modern society, it is very important to develop new approaches to harvest electricity from clean and renewable sources [137]. Dielectric elastomers are known for their ability to convert electrical energy into mechanical energy; however, they can also be applied as generators by using the reverse effect. Moretti et al. developed a dielectric elastomer using commercial polyacrylate 
film (VHB 4905 by $3 \mathrm{M}$ ) and implemented it in a sea wave energy converter (SWEC) that allows for the actual conversion of wave energy into electricity, with a maximum power output of up to $0.87 \mathrm{~W}$ [138]. This indicates that a relevant fraction (up to $18 \%$ ) of the waves' power was converted into electricity [138].

\section{(i) Optical imaging:}

EAPs are also used as the base material for active lens modules to achieve dynamic focus in controllable optical systems over a wide range of adjustments [139]. The advent of optical lens technology that allows for adjustable focus opens up various opportunities, leading to technological advances in optical devices for macro and microimaging with zoom-in/zoom-out capabilities, bioinspired vision, optical communications, and optical measurement systems [139]. For example, Yun et al. [139] used a dielectric elastomer (DE) thin film with annular silver nanowires electrode, a hemispherical lens-structure (made of $\mathrm{DE}$ ) and a ground layer (made of thin annular gold electrode) to develop an active-lens as shown in Figure 10. The active lens module consisted of two parallel active lenses, each with a convex and concave hemispherical lens structure, as shown in Figure 1. When operating with a dynamic input voltage signal, each active lens produces a translational motion that responds bidirectionally to a hybrid driving force, which combines the active electrical response and electrostatic attraction of a thin dielectric elastomer film.

(a)

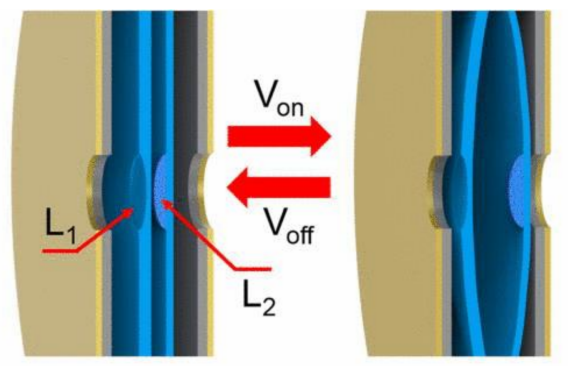

(b)

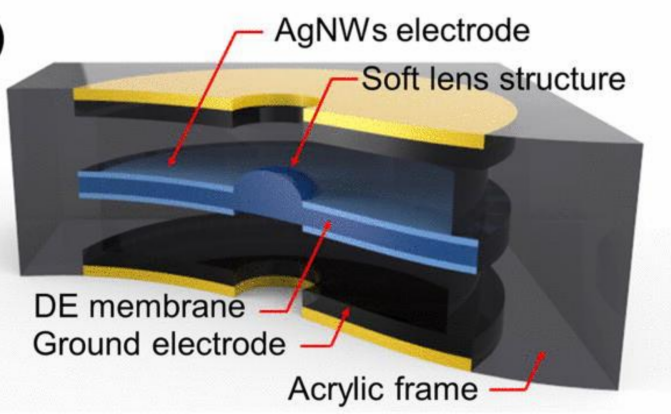

(c)

(d)
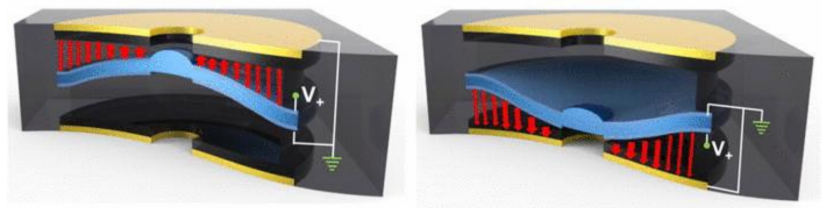

Figure 10. Structural configurations of (a) an active-lens module electrically controlling a gapdistance between the lens structures and (b) an active lens. (c,d) Illustrated operating principle of the active-lens producing bi-directionally controllable movement of the lens-structure responding to a compositive driving force (Reproduced with permission from [139]. Copyright AIP, 2016).

(j) Variable stiffness polymer (VSP):

Variable stiffness polymers (VSPs) are smart materials whose rigidity can be changed depending on environmental cues, such as temperature, light, humidity, electric and magnetic field. One of the recently synthesized VSP is the phase-changing bi-stable electroactive 
polymer (BSEP) [140]. By suiting BSEP's properties, such as insulation, electrical activity, and phase transition characteristics, re-writable photonic papers, smart windows with all-solar spectral modulation, and wearable pressure sensors have been developed [141]. The ink-free re-writable photonic paper was a combination of photonic crystals, shape memory, and the electroactive properties of BSEP. The re-writable paper consists of ferroferric oxide-carbon (Fe3O4@C) core-shell nanoparticles (NPs)-based photonic crystal embedded in a BSEP [141]. The demonstration of rewritable photonic papers is shown in Figure 11. It is designed to acquire various shapes and colours due to the z-direction deformation of the nanocomposite caused by the electric field. It was confirmed that the shapes and colours can last for a long term without energy input, and stored images can be re-written over 500 times without noticeable degradation [141].

(a
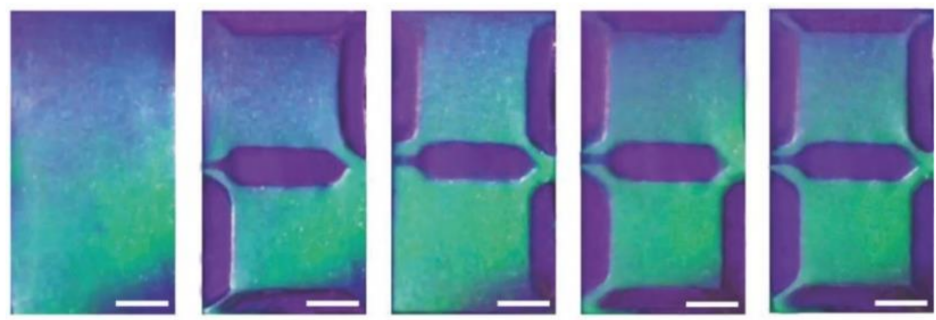

(b
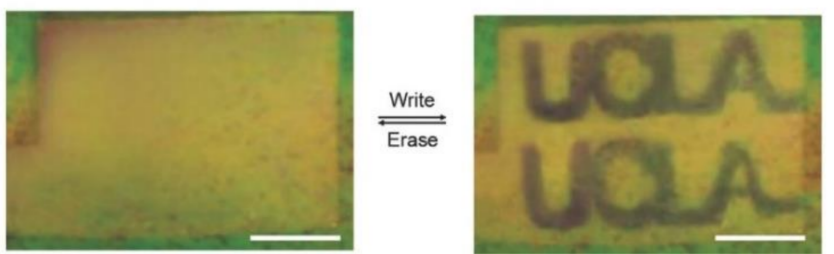

Figure 11. Rewritable photonic papers. (a) Selected images of a photonic paper sequentially demonstrating digits 0-9. (b) Writing and erasing a "UCLA" pattern with font size of 10 on a photonic paper. The scale bars are all $3 \mathrm{~mm}$ in length. (Reproduced with permission from [142]. Copyright Willey and Sons, 2018).

\section{(k) Smart window:}

The smart window is a new technology where many researchers have been focusing their efforts. Bistable electroactive polymer (BSEP) has been used by Xie et al. [141] to produce smart window using BSEP's phase transition characteristics that can switch between the semi-crystalline state and the amorphous state by cooling or heating it at a certain temperature, and it switches between opaque to transparent [141]. The opacity switching characteristics of BSEP have been applied to smart windows, and have been further improved by adding more hydrophilic components to induce microscale phase separation [141]. The resulting smart window has been shown to achieve high solar transmission modulation of $70.2 \%$ and high emission transmission modulation of $80.4 \%$ [141].

\section{Recent Advances and Challenges of EAPs}

The tribological study of polymers and their reaction to stimuli was a concern in the development of EAPs. Their resistance to large electrical and mechanical forces makes them specialized materials for many applications. Other comparable materials, such as electroactive ceramics and alloys have been used for years before the discovery of EAPs. However, the ability of the polymer to shift and accept large amounts of strain for many cycles while still effectively performing the function is a large feat in tribology. In the following subsections, few notable tribological studies and some crucial challenges are briefly highlighted before concluding this review. 


\section{(a) Tribological advances:}

Tribology deals with friction, wear and lubrication [108]. Friction between two interacting surfaces can be reduced by lubricants [143]. Typically lubricants are of three types; solid (nanoparticles such as, graphene, molybdenum disulfide, carbon nanotube), liquid (oils, grease), and gaseous (compressed air, steam) [20]. In the case of EAP, some investigations have been carried out by incorporating nanoparticles inside the polymer matrix. Such incorporation helps in introducing nanoparticles in the interface, when EAPs come into contact with other surfaces [144]. In a 2018 study, Qui et al. [144] added graphene in the polymer matrix and found that, graphene lubricants offered an $81.3 \%$ reduction in friction coefficient. Graphene also lead to a $61.8 \%$ reduction in wear scar diameter [144]. Also, EAP coating helps in reducing friction and wear. For example, Gu et al. studied $\mathrm{SiO}_{2} /$ polycarbonate composite coating at and observed that the friction was significantly lowered by adding the silica nanoparticles and the wear depth was reduced by $65 \mathrm{~nm}$ (from $161 \mathrm{~nm}$ to $95 \mathrm{~nm}$ ) $[145,146]$. EAPs have various applications in the field of tribology and thus reducing friction.

\section{(b) Corrosion reduction:}

Corrosion is detrimental to material life cycle and therefore coating is often used to reduce corrosion. Metals, especially different kinds of steels, are prone to corrosion [147]. EAP coatings are particularly effective to prevent corrosion on cold-rolled steel (CRS) [148]. Huang et al. [148] synthesized a superhydrophobic fluorinated polyimide (HEFPI) from aniline trimer and 4,4'-(Hexafluoroisopropylidene) diphthalic anhydride and coated on cold rolled steel. It exhibited a contact angle of $157^{\circ}$. This makes HEFPI a great EAP film for advanced anti corrosion materials. Hydrophobicity is important to prevent water accumulation from surface, and thus significantly reduces corrosion. Moreover, Ji et al. [149] reported that when an electroactive polyimide coating with a biomimetic rose-petal like structure was applied, it nearly doubled (from $87^{\circ}$ to $150^{\circ}$ ) the hydrophobicity of the surface compared to smooth coating made of only electroactive polyimide [149]. The rose-petal-like structure made it less prone to form water droplets and prevented a passive layer of metal oxide, and thus reduced corrosion [149].

\section{(c) Notable challenges:}

Various applications using dielectric elastomer actuators (DEAs) include soft robot hands, locomotive robots, and wearable robots [150]. Besides, there are additional potential application areas, such as cell manipulation in biology, automatic grippers in agricultural robotics, micropumps, and valves in microfluidic systems, active vibration isolation in mechanical structures, and lightweight speakers in acoustic devices [150-152]. Dielectric elastomers are good candidates for artificial muscles, but some challenges for the widespread use of DEA, such as high driving voltage, require additional power circuits. This could be the most serious issue for safety, especially for wearable applications [150]. The DEA output response is proportional to the input voltage and inversely proportional to the thickness [150]. Therefore, it is necessary to reduce the thickness of the DEA in order to maintain the output at a lower drive voltage [150]. In order to solve this problem, multiple stacking of thin films has been considered [150]. However, the production of layered DEAs currently faces a variety of challenges, such as high precision requirements and time-intensive labor when stacked manually [150]. In the future, the performance of layered DEAs needs to be improved by developing new manufacturing methods. In addition, it is necessary to improve the low contraction force due to the softness of the material [150]. Unlike human muscle, DEA usually contracts due to the restoring force of the material by removing heat, but its use is limited due to its limited thermal contraction force. A new design approach is required to generate high contraction forces [150]. DEA durability is also an important issue. Since DAE is a type of polymer, it has the same weaknesses as traditional polymers that are not resistant to sharp cuts, high pressure, and UV (ultraviolet) light and heat [150]. Also, biocompatibility and biodegradability could be important aspects to be addressed for sustainable waste management of EAP 
devices $[153,154]$. Biocompatibility and biodegradability could be an issue, which needs to be addressed for sustainable waste management of EAP devices [154,155]. Moreover, the reduction of friction and wear to enhance life endurance demands detailed tribological studies. Overcoming all these issues is important for the widespread use of EAP in the future.

\section{Conclusions}

The unique functionalities of electroactive polymers have motivated a large amount of research that spans many engineering fields. Coinciding with the plentiful variety of EAPs, there are also numerous ways to fabricate these devices. Depending on the application, specific properties might be required. These can be eventually found in EAPs and not in other materials. EAPs have potential as soft actuators since they do not need to be integrated into rigid components to function, quite differently from previous grades of electro-mechanical actuators/sensors. In the growing field of wearable and implanted electronics, this allows for sensors or mechanisms to provide outstanding performance not previously achieved. In the field of prosthetics, synthetic muscles could aim to replace muscle transplants or mechanically actuated devices that often lack finesse and the delicacy that humans are unconsciously capable of delivering. Due to the nature of EAPs and the significantly lower voltage requirements compared to traditional prosthetics, the application of this technology stands to increase safety. The noiseless activation is an additional quality that will benefit users.

Beyond the category of wearable technology, the field of robotics would also benefit from the integration of soft actuators. Novel robots are being developed, such as those that perform serpentine motion and are capable of traversing a wide variety of difficult terrains. Robots that need to interface with humans will crucially benefit from the safety of having soft actuators for the minimized risk of injury. Underwater applications stand to benefit from noiseless propulsion, which could minimize the detrimental effects of motorized aquatic vehicles on marine life. While ionic EAPs may consist of polymer sandwiches impregnated with ionic liquids, electronic EAPs require no liquid components, although they require high voltage to activate. Depending on the application, different materials may be used with the EAPs to specify an electric response to different stimuli such as movement, heat, magnetic fields, and even light. One of the most reoccurring similarities in the recent research studies on EAPs production is the reduction of manufacturing costs and complexity. Additionally, despite the high strain EAPs may exhibit, fragility is still a prohibitive factor for the use of these technologies in harsh environments such as high temperatures or high forces. A limiting factor to the production of EAPs is the ability to control the structure nearly to the atomic level. The higher the precision, the more specially tuned and effective the EAP may become; however, this is at the expense of cost and manufacturing time. Automated processes, such as $3 \mathrm{~d}$ printing or electrospinning, are aiming at improving the manufacturability of these new materials. Progress has indeed been accelerating in recent years; however, more research is still needed to achieve a widespread understanding in which the individual properties and categories of EAPs will better connect.

Author Contributions: Conceptualization, M.H.R. and P.L.M.; Methodology, M.H.R., H.W., A.G., Y.H., C.D., L.L.; writing—original draft, H.W., A.G., Y.H., C.D., L.L., M.H.R.; writing-review and editing, M.H.R., H.W., P.L.M.; visualization, M.H.R.; supervision, M.H.R.; project administration, P.L.M. All authors have read and agreed to the published version of the manuscript.

Funding: We acknowledge the support and facilities from the Department of Mechanical Engineering at the University of Nevada at Reno.

Institutional Review Board Statement: Not applicable.

Informed Consent Statement: Not applicable.

Data Availability Statement: All data related to this paper was accessed on or before 9 September 2021. 
Acknowledgments: We acknowledge the help of Ashish Kasar during this review.

Conflicts of Interest: The authors declare no conflict of interest. The funders had no role in the design of the study; in the collection, analyses, or interpretation of data; in the writing of the manuscript, or in the decision to publish the results.

\section{References}

1. Bar-Cohen, Y.; Anderson, I.A. Electroactive polymer (EAP) actuators-Background review. Mech. Soft Mater. 2019, 1, 5. [CrossRef]

2. Bar-Cohen, Y.; Zhang, Q. Electroactive Polymer Actuators and Sensors. MRS Bull. 2008, 33, 173-181. [CrossRef]

3. Hunt, A.; Chen, Z.; Tan, X.; Kruusmaa, M. An integrated electroactive polymer sensor-actuator: Design, model-based control, and performance characterization. Smart Mater. Struct. 2016, 25, 035016. [CrossRef]

4. Palza, H.; Zapata, P.A.; Angulo-Pineda, C. Electroactive Smart Polymers for Biomedical Applications. Materials 2019, 12, 277. [CrossRef]

5. Khuyen, N.Q.; Kiefer, R.; Elhi, F.; Anbarjafari, G.; Martinez, J.G.; Tamm, T. A biomimetic approach to increasing soft actuator performance by friction reduction. Polymers 2020, 12, 1120. [CrossRef] [PubMed]

6. Neuhaus, R.; Zahiri, N.; Petrs, J.; Tahouni, Y.; Siegert, J.; Kolaric, I.; Dahy, H.; Bauernhansl, T. Integrating ionic electroactive polymer actuators and sensors into adaptive building skins: Potentials and limitations. Front. Built Environ. 2020, 6, 95. [CrossRef]

7. Research and Markets. Electroactive Polymer Market by Type (Conductive Plastic, Inherently Conductive Polymer, Inherently Dissipative Polymer), Application (ESD Protection, EMI Shielding, Actuators, Capacitors, Batteries, Sensors), and Region-Global Forecast to 2022. Available online: https: / / www.researchandmarkets.com/reports/4460750/electroactive-polymer-market-bytype-conductive (accessed on 11 July 2021).

8. Tagarielli, V.L.; Hildick-Smith, R.; Huber, J.E. Electro-mechanical properties and electrostriction response of a rubbery polymer for EAP applications. Int. J. Solids Struct. 2012, 49, 3409-3415. [CrossRef]

9. Põldsalu, I.; Johanson, U.; Tamm, T.; Punning, A.; Greco, F.; Peikolainen, A.-L.; Kiefer, R.; Aabloo, A. Mechanical and electromechanical properties of EAP actuators with inkjet printed electrodes. Synth. Met. 2018, 246, 122-127. [CrossRef]

10. Abidi, H.; Cianchetti, M. On intrinsic safety of soft robots. Front. Robot. AI 2017, 4, 5. [CrossRef]

11. Onal, C.D.; Rus, D. Autonomous undulatory serpentine locomotion utilizing body dynamics of a fluidic soft robot. Bioinspir. Biomim. 2013, 8, 026003. [CrossRef] [PubMed]

12. Forouharshad, M.; King, S.G.; Buxton, W.; Kunovski, P.; Stolojan, V. Textile-Compatible, Electroactive Polyvinylidene Fluoride Electrospun Mats for Energy Harvesting. Macromol. Chem. Phys. 2019, 220, 1900364. [CrossRef]

13. Koo, I.M.; Jung, K.; Koo, J.C.; Nam, J.-D.; Lee, Y.K.; Choi, H.R. Development of soft-actuator-based wearable tactile display. IEEE Trans. Robot. 2008, 24, 549-558. [CrossRef]

14. Research and Markets. Global Electroactive Polymer Market, 2018-2022 by Type, Application, and Region; Cision PR Newswire: New York, NY, USA, 2021.

15. Jo, C.; Pugal, D.; Oh, I.-K.; Kim, K.J.; Asaka, K. Recent advances in ionic polymer-metal composite actuators and their modeling and applications. Prog. Polym. Sci. 2013, 38, 1037-1066. [CrossRef]

16. Hong, W.; Almomani, A.; Chen, Y.; Jamshidi, R.; Montazami, R. Soft ionic electroactive polymer actuators with tunable non-linear angular deformation. Materials 2017, 10, 664. [CrossRef] [PubMed]

17. Palmre, V.; Brandell, D.; Mäeorg, U.; Torop, J.; Volobujeva, O.; Punning, A.; Johanson, U.; Kruusmaa, M.; Aabloo, A. Nanoporous carbon-based electrodes for high strain ionomeric bending actuators. Smart Mater. Struct. 2009, 18, 095028. [CrossRef]

18. Kim, O.; Kim, S.J.; Park, M.J. Low-voltage-driven soft actuators. Chem. Commun. 2018, 54, 4895-4904. [CrossRef]

19. Cai, M.; Yu, Q.; Liu, W.; Zhou, F. Ionic liquid lubricants: When chemistry meets tribology. Chem. Soc. Rev. 2020, 49, 7753-7818. [CrossRef] [PubMed]

20. Rahman, M.H.; Warneke, H.; Webbert, H.; Rodriguez, J.; Austin, E.; Tokunaga, K.; Rajak, D.K.; Menezes, P.L. Water-Based Lubricants: Development, Properties, and Performances. Lubricants 2021, 9, 73. [CrossRef]

21. Rinne, P.; Põldsalu, I.; Ratas, H.K.; Kruusamäe, K.; Johanson, U.; Tamm, T.; Põhako-Esko, K.; Punning, A.; Peikolainen, A.-L.; Kaasik, F. Fabrication of Carbon-Based Ionic Electromechanically Active Soft Actuators. JoVE (J. Vis. Exp.) 2020, e61216. [CrossRef]

22. Yip, J.; Feng, L.S.; Hang, C.W.; Marcus, Y.C.W.; Wai, K.C. Experimentally validated improvement of IPMC performance through alternation of pretreatment and electroless plating processes. Smart Mater. Struct. 2010, 20, 015009. [CrossRef]

23. Kim, K.J.; Shahinpoor, M. Ionic polymer-metal composites: II. Manufacturing techniques. Smart Mater. Struct. 2003, 12, 65. [CrossRef]

24. Rasouli, H.; Naji, L.; Hosseini, M.G. Electrochemical and electromechanical behavior of Nafion-based soft actuators with PPy/CB/MWCNT nanocomposite electrodes. RSC Adv. 2017, 7, 3190-3203. [CrossRef]

25. Malinauskas, A. Chemical deposition of conducting polymers. Polymer 2001, 42, 3957-3972. [CrossRef]

26. Hu, F.; Xue, Y.; Xu, J.; Lu, B. PEDOT-based conducting polymer actuators. Front. Robot. AI 2019, 6, 114. [CrossRef] [PubMed]

27. Kaneto, K.; Fujisue, H.; Kunifusa, M.; Takashima, W. Conducting polymer soft actuators based on polypyrrole films-Energy conversion efficiency. Smart Mater. Struct. 2007, 16, S250. [CrossRef]

28. Ramírez-García, S.; Diamond, D. Biomimetic, low power pumps based on soft actuators. Sens. Actuators A Phys. 2007, 135, 229-235. [CrossRef] 
29. Jo, A.; Huet, C.; Naguib, H.E. Template-Assisted Self-Assembly of Conductive Polymer Electrodes for Ionic Electroactive Polymers. Front. Bioeng. Biotechnol. 2020, 8, 837. [CrossRef]

30. Zhang, C.; He, B.; Wang, Z.; Zhou, Y.; Ming, A. Application and Analysis of an Ionic Liquid Gel in a Soft Robot. Adv. Mater. Sci. Eng. 2019, 2019, 2857282. [CrossRef]

31. Fukushima, T.; Kosaka, A.; Ishimura, Y.; Yamamoto, T.; Takigawa, T.; Ishii, N.; Aida, T. Molecular ordering of organic molten salts triggered by single-walled carbon nanotubes. Science 2003, 300, 2072-2074. [CrossRef]

32. Terasawa, N. High-performance transparent actuator made from Poly (dimethylsiloxane)/Ionic liquid gel. Sens. Actuators $B$ Chem. 2018, 257, 815-819. [CrossRef]

33. Goswami, S.; Gonçalves, P.; Cidade, M.T. Electrorheological behavior of suspensions of camphorsulfonic acid (CSA) doped polyaniline nanofibers in silicone oil. Phys. Scr. 2017, 92, 075801. [CrossRef]

34. Linzhi, L.I.; Shujuan, G.A.O. Polyaniline (PANI) and $\mathrm{BaTiO}_{3}$ composite nanotube with high suspension performance in electrorheological fluid. Mater. Today Commun. 2020, 24, 100993. [CrossRef]

35. Xi, Z.; Ma, J.; Sun, W.; Wang, B.; Hao, C. Synthesis and electrorheological properties of hierarchical and core-shell MoS $\mathrm{M} \mathrm{TiO}_{2}$ nanocomposite. J. Solid State Chem. 2020, 290, 121601. [CrossRef]

36. Tang, J.; Wen, X.; Liu, Z.; Wang, J.; Zhang, P. Synthesis and electrorheological performances of 2D PANI/TiO 2 nanosheets. Colloids Surf. A Physicochem. Eng. Asp. 2018, 552, 24-31. [CrossRef]

37. Fei, J.; Cui, Y.; Yan, X.; Yang, Y.; Su, Y.; Li, J. Formation of PANI tower-shaped hierarchical nanostructures by a limited hydrothermal reaction. J. Mater. Chem. 2009, 19, 3263-3267. [CrossRef]

38. Wu, S.; Tian, S.; Menezes, P.L.; Xiong, G. Carbon solid lubricants: Role of different dimensions. Int. J. Adv. Manuf. Technol. 2020, 107, 3875-3895. [CrossRef]

39. Elhi, F.; Karu, K.; Rinne, P.; Nadel, K.-A.; Järvekülg, M.; Aabloo, A.; Tamm, T.; Ivaništšev, V.; Põhako-Esko, K. Understanding the Behavior of Fully Non-Toxic Polypyrrole-Gelatin and Polypyrrole-PVdF Soft Actuators with Choline Ionic Liquids. Actuators 2020, 9, 40. [CrossRef]

40. Kang, Y.J.; Yoo, Y.; Kim, W. 3-V solid-state flexible supercapacitors with ionic-liquid-based polymer gel electrolyte for AC line filtering. ACS Appl. Mater. Interfaces 2016, 8, 13909-13917. [CrossRef] [PubMed]

41. Lee, J.Y.; Wang, H.S.; Yoon, B.R.; Han, M.J.; Jho, J.Y. Radiation-Grafted Fluoropolymers Soaked with Imidazolium-Based Ionic Liquids for High-Performance Ionic Polymer-Metal Composite Actuators. Macromol. Rapid Commun. 2010, 31, $1897-1902$. [CrossRef] [PubMed]

42. Wang, T.; Farajollahi, M.; Choi, Y.S.; Lin, I.T.; Marshall, J.E.; Thompson, N.M.; Kar-Narayan, S.; Madden, J.D.W.; Smoukov, S.K. Electroactive polymers for sensing. Interface Focus 2016, 6, 20160026. [CrossRef] [PubMed]

43. Araromi, O.A.; Conn, A.T.; Ling, C.S.; Burgess, S.C.; Vaidyanathan, R. A Novel Fabrication Set-up for the Flexible Production of Silicone Based EAP “Artificial Muscle” Actuators. Des. Nat. V 2010, 138, 289-300.

44. Bar-Cohen, Y. Electroactive Polymer (EAP) Actuators as Artificial Muscles: Reality, Potential, and Challenges; SPIE Press: Bellingham, WA, USA, 2004; Volume 136.

45. Pelrine, R.E.; Kornbluh, R.D.; Joseph, J.P. Electrostriction of polymer dielectrics with compliant electrodes as a means of actuation. Sens. Actuators A Phys. 1998, 64, 77-85. [CrossRef]

46. Trujillo, R.; Mou, J.; Phelan, P.E.; Chau, D.S. Investigation of electrostrictive polymers as actuators for mesoscale devices. Int. J. Adv. Manuf. Technol. 2004, 23, 176-182. [CrossRef]

47. Mirfakhrai, T.; Madden, J.D.; Baughman, R.H. Polymer artificial muscles. Mater. Today 2007, 10, 30-38. [CrossRef]

48. Ask, A.; Menzel, A.; Ristinmaa, M. Electrostriction in electro-viscoelastic polymers. Mech. Mater. 2012, 50, 9-21. [CrossRef]

49. Qin, H.; Ning, N.; Tian, M.; Zhang, L.; Mi, J. Effect of adding epoxy groups to poly (butyl acrylate) on electro-viscoelastic response: Insight from molecular dynamics simulation. Polymer 2020, 193, 122349. [CrossRef]

50. Eder-Goy, D.; Zhao, Y.; Xu, B.-X. Dynamic pull-in instability of a prestretched viscous dielectric elastomer under electric loading. Acta Mech. 2017, 228, 4293-4307. [CrossRef]

51. Zhang, Q.M.; Bharti, V.; Zhao, X. Giant Electrostriction and Relaxor Ferroelectric Behavior in Electron-Irradiated Poly(vinylidene fluoride-trifluoroethylene) Copolymer. Science 1998, 280, 2101-2104. [CrossRef]

52. Chu, B.; Zhou, X.; Ren, K.; Neese, B.; Lin, M.; Wang, Q.; Bauer, F.; Zhang, Q.M. A Dielectric Polymer with High Electric Energy Density and Fast Discharge Speed. Science 2006, 313, 334-336. [CrossRef]

53. Neese, B.; Chu, B.; Lu, S.-G.; Wang, Y.; Furman, E.; Zhang, Q.M. Large Electrocaloric Effect in Ferroelectric Polymers near Room Temperature. Science 2008, 321, 821-823. [CrossRef]

54. Chen, X.Z.; Li, Q.; Chen, X.; Guo, X.; Ge, H.X.; Liu, Y.; Shen, Q.D. Nano-Imprinted Ferroelectric Polymer Nanodot Arrays for High Density Data Storage. Adv. Funct. Mater. 2013, 23, 3124-3129. [CrossRef]

55. Palto, S.P.; Yudin, S.G.; Zlatkin, A.; Blinov, L.M.; Sorokin, A.V.; Bune, A.V.; Ducharme, S.; Fridkin, V.M. Two-dimensional ferroelectric films. Nature 1998, 391, 874-877. [CrossRef]

56. Li, F.; Zhang, S.; Damjanovic, D.; Chen, L.Q.; Shrout, T.R. Local structural heterogeneity and electromechanical responses of ferroelectrics: Learning from relaxor ferroelectrics. Adv. Funct. Mater. 2018, 28, 1801504. [CrossRef]

57. Bauer, F. Relaxor fluorinated polymers: Novel applications and recent developments. IEEE Trans. Dielectr. Electr. Insul. 2010, 17, 1106-1112. [CrossRef] 
58. Xia, F.; Cheng, Z.Y.; Xu, H.; Li, H.; Zhang, Q.; Kavarnos, G.J.; Ting, R.Y.; Abdul-Sadek, G.; Belfield, K.D. High electromechanical responses in a poly (vinylidene fluoride-trifluoroethylene-chlorofluoroethylene) terpolymer. Adv. Mater. 2002, 14, $1574-1577$. [CrossRef]

59. Chen, D.; Pei, Q. Electronic muscles and skins: A review of soft sensors and actuators. Chem. Rev. 2017, 117, 11239-11268. [CrossRef] [PubMed]

60. Benslimane, M.Y.; Kiil, H.E.; Tryson, M.J. Dielectric electro-active polymer push actuators: Performance and challenges. Polym. Int. 2010, 59, 415-421. [CrossRef]

61. Berardi, U. Dielectric electroactive polymer applications in buildings. Intell. Build. Int. 2010, 2, 167-178.

62. Saha, S.; Bhowmick, A.K.; Kumar, A.; Patra, K.; Cottinet, P.-J.; Thetpraphi, K. Polyvinylidene Fluoride/Hydrogenated Nitrile Rubber-Based Flexible Electroactive Polymer Blend and Its Nanocomposites with Improved Actuated Strain: Characterization and Analysis of Electrostrictive Behavior. Ind. Eng. Chem. Res. 2020, 59, 3413-3424. [CrossRef]

63. Qian, X.; Wu, S.; Furman, E.; Zhang, Q.; Su, J. Ferroelectric polymers as multifunctional electroactive materials: Recent advances, potential, and challenges. MRS Commun. 2015, 5, 115-129. [CrossRef]

64. Feng, C.; Rajapaksha, C.P.H.; Cedillo, J.M.; Piedrahita, C.; Cao, J.; Kaphle, V.; Lüssem, B.; Kyu, T.; Jákli, A. Electroresponsive ionic liquid crystal elastomers. Macromol. Rapid Commun. 2019, 40, 1900299. [CrossRef] [PubMed]

65. Shankar, R.; Ghosh, T.K.; Spontak, R.J. Mechanical and actuation behavior of electroactive nanostructured polymers. Sens. Actuators A Phys. 2009, 151, 46-52. [CrossRef]

66. Park, I.-S.; Kim, S.-M.; Kim, K.J. Mechanical and thermal behavior of ionic polymer-metal composites: Effects of electroded metals. Smart Mater. Struct. 2007, 16, 1090. [CrossRef]

67. UKEssays. Classes of Electroactive Polymer Materials. Available online: https://www.ukessays.com/essays/chemistry/classesof-electroactive-polymer-materials.php?vref=1 (accessed on 11 July 2021).

68. Xu, Y.; Jia, W.; Zhang, Y.; Wang, F.; Zhao, G.; Zang, D. Mechanical properties analysis and surface composition research of Ag-IPMC. Sens. Actuators A Phys. 2021, 319, 112565. [CrossRef]

69. Cuenot, S.; Demoustier-Champagne, S.; Nysten, B. Elastic modulus of polypyrrole nanotubes. Phys. Rev. Lett. 2000, 85, 1690. [CrossRef] [PubMed]

70. Sharma, R.K.; Rastogi, A.C.; Desu, S.B. Pulse polymerized polypyrrole electrodes for high energy density electrochemical supercapacitor. Electrochem. Commun. 2008, 10, 268-272. [CrossRef]

71. Hara, S.; Zama, T.; Sewa, S.; Takashima, W.; Kaneto, K. Highly stretchable and powerful polypyrrole linear actuators. Chem. Lett. 2003, 32, 576-577. [CrossRef]

72. Huang, Z.-D.; Liang, R.; Zhang, B.; He, Y.-B.; Kim, J.-K. Evolution of flexible 3D graphene oxide/carbon nanotube/polyaniline composite papers and their supercapacitive performance. Compos. Sci. Technol. 2013, 88, 126-133. [CrossRef]

73. Okuzaki, H.; Suzuki, H.; Ito, T. Electromechanical properties of poly (3,4-ethylenedioxythiophene)/poly (4-styrene sulfonate) films. J. Phys. Chem. B 2009, 113, 11378-11383. [CrossRef] [PubMed]

74. Wang, X.-S.; Feng, X.-Q. Effects of thickness on mechanical properties of conducting polythiophene films. J. Mater. Sci. Lett. 2002, 21, 715-717. [CrossRef]

75. Vijeth, H.; Ashokkumar, S.P.; Yesappa, L.; Niranjana, M.; Vandana, M.; Devendrappa, H. Flexible and high energy density solid-state asymmetric supercapacitor based on polythiophene nanocomposites and charcoal. RSC Adv. 2018, 8, 31414-31426.

76. Akagi, K.; Sakamaki, K.; Shirakawa, H.; Kyotani, H. Polyacetylene films prepared by intrinsic non-solvent polymerization method-mechanical properties and electrical conductivities. Synth. Met. 1995, 69, 29-30. [CrossRef]

77. Cao, Y.; Smith, P.; Heeger, A.J. Mechanical and electrical properties of polyacetylene films oriented by tensile drawing. Polymer 1991, 32, 1210-1218. [CrossRef]

78. Liu, Y.; Liu, L.; Zhang, Z.; Leng, J. Dielectric elastomer film actuators: Characterization, experiment and analysis. Smart Mater. Struct. 2009, 18, 095024. [CrossRef]

79. Machado, J.M.; Masse, M.A.; Karasz, F.E. Anisotropic mechanical properties of uniaxially oriented electrically conducting poly (p-phenylene vinylene). Polymer 1989, 30, 1992-1996. [CrossRef]

80. Cheng, Z.Y.; Bharti, V.; Xu, T.B.; Xu, H.; Mai, T.; Zhang, Q.M. Electrostrictive poly (vinylidene fluoride-trifluoroethylene) copolymers. Sens. Actuators A Phys. 2001, 90, 138-147. [CrossRef]

81. Haddou, G.; Dandurand, J.; Dantras, E.; Maiduc, H.; Thai, H.; Giang, N.V.; Trung, T.H.; Ponteins, P.; Lacabanne, C. Mechanical properties of continuous bamboo fiber-reinforced biobased polyamide 11 composites. J. Appl. Polym. Sci. 2019, 136, 47623. [CrossRef]

82. Youssef, G.; Gupta, V. Dynamic tensile strength of polyurea. J. Mater. Res. 2012, 27, 494. [CrossRef]

83. Wang, Y.; Zhou, X.; Lin, M.; Zhang, Q.M. High-energy density in aromatic polyurea thin films. Appl. Phys. Lett. 2009, 94, 202905. [CrossRef]

84. Mohammadi, B.; Yousefi, A.A.; Bellah, S.M. Effect of tensile strain rate and elongation on crystalline structure and piezoelectric properties of PVDF thin films. Polym. Test. 2007, 26, 42-50. [CrossRef]

85. Engineering \& Manufacturing Services. Polyfluor: Breda, The Netherlands. Available online: https://www.polyfluor.nl/en/ materials/pvdf/ (accessed on 10 September 2021). 
86. Paul, B.K.; Kar, S.; Bandyopadhyay, P.; Basu, R.; Das, S.; Bhar, D.S.; Manchanda, R.K.; Khurana, A.; Nayak, D.; Nandy, P. Significant enhancement of dielectric and conducting properties of electroactive polymer polyvinylidene fluoride films: An innovative use of Ferrum metallicum at different concentrations. Indian J. Res. Homoeopath. 2016, 10, 52-58.

87. Bar-Cohen, Y.; Sherrit, S.; Lih, S.-S. Characterization of the electromechanical properties of EAP materials. In Smart Structures and Materials 2001: Electroactive Polymer Actuators and Devices; International Society for Optics and Photonics: Bellingham, WA, USA, 2001; pp. 319-327.

88. Brochu, P. Dielectric Elastomers for Actuation and Energy Harvesting; University of California: Los Angeles, CA, USA, 2012.

89. Peng, H.; Sun, X.; Weng, W.; Fang, X. 5-Energy Harvesting Based on Polymer. In Polymer Materials for Energy and Electronic Applications; Peng, H., Sun, X., Weng, W., Fang, X., Eds.; Academic Press: Cambridge, MA, USA, 2017; pp. 151-196.

90. Peng, H.; Sun, X.; Weng, W.; Fang, X. Polymer Materials for Energy and Electronic Applications; Academic Press: Cambridge, MA, USA, 2016.

91. Boczkowska, A.; Leonowicz, M. Intelligent materials for intelligent textiles. Fibres Text. East. Eur. 2006, $14,13-17$.

92. Vu-Cong, T.; Jean-Mistral, C.; Sylvestre, A.J. Impact of the nature of the compliant electrodes on the dielectric constant of acrylic and silicone electroactive polymers. Smart Mater. Struct. 2012, 21, 105036. [CrossRef]

93. Kofod, G.; Kornbluh, R.D.; Pelrine, R.; Sommer-Larsen, P. Actuation response of polyacrylate dielectric elastomers. In Smart Structures and Materials 2001: Electroactive Polymer Actuators and Devices; International Society for Optical Engineering: Bellingham, WA, USA, 2001; pp. 141-147.

94. Wissler, M.; Mazza, E.J.S.; Physical, A.A. Electromechanical coupling in dielectric elastomer actuators. Sens. Actuators A Phys. 2007, 138, 384-393. [CrossRef]

95. Jean-Mistral, C.; Sylvestre, A.; Basrour, S.; Chaillout, J.J. Dielectric properties of polyacrylate thick films used in sensors and actuators. Smart Mater. Struct. 2010, 19, 075019. [CrossRef]

96. Gonzalez, D.; Garcia, J.; Newell, B. Electromechanical characterization of a 3D printed dielectric material for dielectric electroactive polymer actuators. Sens. Actuators A Phys. 2019, 297, 111565. [CrossRef]

97. Li, B.; Chen, H.; Qiang, J.; Hu, S.; Zhu, Z.; Wang, Y. Effect of mechanical pre-stretch on the stabilization of dielectric elastomer actuation. J. Phys. D Appl. Phys. 2011, 44, 155301. [CrossRef]

98. Choi, H.R.; Jung, K.; Chuc, N.H.; Jung, M.; Koo, I.; Koo, J.; Lee, J.; Lee, J.; Nam, J.; Cho, M. Effects of prestrain on behavior of dielectric elastomer actuator. In Smart Structures and Materials 2005: Electroactive Polymer Actuators and Devices (EAPAD); International Society for Optics and Photonics: Bellingham, WA, USA, 2005; pp. 283-291.

99. McKay, T.G.; Calius, E.; Anderson, I.A. The dielectric constant of 3M VHB: A parameter in dispute. In Electroactive Polymer Actuators and Devices (EAPAD); International Society for Optics and Photonics: Bellingham, WA, USA, 2009.

100. Kofod, G.; Sommer-Larsen, P.; Kornbluh, R.; Pelrine, R. Actuation response of polyacrylate dielectric elastomers. J. Intell. Mater. Syst. Struct. 2003, 14, 787-793. [CrossRef]

101. Fukushima, T.; Asaka, K.; Kosaka, A.; Aida, T. Fully plastic actuator through layer-by-layer casting with ionic-liquid-based bucky gel. Angew. Chem. Int. Ed. 2005, 44, 2410-2413. [CrossRef]

102. Xiao, J.; Gama, B.; Gillespie Jr, J. An analytical molecular structural mechanics model for the mechanical properties of carbon nanotubes. Int. J. Solids Struct. 2005, 42, 3075-3092. [CrossRef]

103. Meo, M.; Rossi, M. Prediction of Young's modulus of single wall carbon nanotubes by molecular-mechanics based finite element modelling. Compos. Sci. Technol. 2006, 66, 1597-1605. [CrossRef]

104. Yu, M.-F.; Lourie, O.; Dyer, M.J.; Moloni, K.; Kelly, T.F.; Ruoff, R.S. Strength and breaking mechanism of multiwalled carbon nanotubes under tensile load. Science 2000, 287, 637-640. [CrossRef]

105. Kim, H.-i.; Wang, M.; Lee, S.K.; Kang, J.; Nam, J.-D.; Ci, L.; Suhr, J. Tensile properties of millimeter-long multi-walled carbon nanotubes. Sci. Rep. 2017, 7, 9512. [CrossRef]

106. Domun, N.; Hadavinia, H.; Zhang, T.; Sainsbury, T.; Liaghat, G.; Vahid, S. Improving the fracture toughness and the strength of epoxy using nanomaterials-A review of the current status. Nanoscale 2015, 7, 10294-10329. [CrossRef] [PubMed]

107. Punning, A.; Kim, K.J.; Palmre, V.; Vidal, F.; Plesse, C.; Festin, N.; Maziz, A.; Asaka, K.; Sugino, T.; Alici, G. Ionic electroactive polymer artificial muscles in space applications. Sci. Rep. 2014, 4, 6913. [CrossRef] [PubMed]

108. Tribology for Scientists and Engineers; Menezes, P.L.; Nosonovsky, M.; Ingole, S.P.; Kailas, S.V.; Lovell, M.R. (Eds.) Tribology for Scientists and Engineers; Springer: New York, NY, USA, 2013.

109. Mun, S.; Yun, S.; Nam, S.; Park, S.K.; Park, S.; Park, B.J.; Lim, J.M.; Kyung, K.-U. Electro-active polymer based soft tactile interface for wearable devices. IEEE Trans. Haptics 2018, 11, 15-21. [CrossRef] [PubMed]

110. Lyons, M.E.G. Electroactive Polymer Electrochemistry: Part 1: Fundamentals; Springer Science \& Business Media: Berlin, Germany, 2013.

111. Ahmed, M.; Billah, M.M. Smart material-actuated flexible tendon-based snake robot. Int. J. Adv. Robot. Syst. 2016, 13, 89. [CrossRef]

112. Jung, K.; Koo, J.C.; Lee, Y.K.; Choi, H.R. Artificial annelid robot driven by soft actuators. Bioinspir. Biomim. 2007, 2, S42. [CrossRef] [PubMed]

113. Hines, L.; Petersen, K.; Lum, G.Z.; Sitti, M. Soft actuators for small-scale robotics. Adv. Mater. 2017, 29, 1603483. [CrossRef]

114. Bar-Cohen, Y. Bionic: Bionic humans using EAP as artificial muscles reality and challenges. Int. J. Adv. Robot. Syst. $2004,1,21$. [CrossRef] 
115. Biddiss, E.; Chau, T. Dielectric elastomers as actuators for upper limb prosthetics: Challenges and opportunities. Med. Eng. Phys. 2008, 30, 403-418. [CrossRef] [PubMed]

116. Hitchcock, R.N.; Humphreys, D.W.; Muir, A.H.; Zarrabi, A. Audio Devices with Electroactive Polymer Actuators Noise Cancellation. Google Patents W02014100573A2, 26 June 2014.

117. Heydt, R.P.; Pelrine, R.E.; Kornbluh, R.D.; Bonwit, N.A.; Eckerle, J.S. Compliant electroactive polymer transducers for sonic applications. Acoust. Soc. Am. J. 2011, 130, 1078. [CrossRef]

118. Abbad, A.; Rabenorosoa, K.; Ouisse, M.; Atalla, N. Adaptive Helmholtz resonator based on electroactive polymers: Modeling, characterization, and control. Smart Mater. Struct. 2018, 27, 105029. [CrossRef]

119. Qiu, Y.; Zhang, E.; Plamthottam, R.; Pei, Q. Dielectric elastomer artificial muscle: Materials innovations and device explorations. Acc. Chem. Res. 2019, 52, 316-325. [CrossRef]

120. Palumbo, F.; Wen, C.; Lombardo, S.; Pazos, S.; Aguirre, F.; Eizenberg, M.; Hui, F.; Lanza, M. A review on dielectric breakdown in thin dielectrics: Silicon dioxide, high-k, and layered dielectrics. Adv. Funct. Mater. 2020, 30, 1900657. [CrossRef]

121. Fannir, A.; Temmer, R.; Nguyen, G.T.M.; Cadiergues, L.; Laurent, E.; Madden, J.D.W.; Vidal, F.; Plesse, C. Linear Artificial Muscle Based on Ionic Electroactive Polymer: A Rational Design for Open-Air and Vacuum Actuation. Adv. Mater. Technol. 2019, 4, 1800519. [CrossRef]

122. Klontzas, M.E.; Akoumianakis, I.D.; Vagios, I.; Karantanas, A.H. MR imaging findings of medial tibial crest friction. Eur. J. Radiol. 2013, 82, e703-e706. [CrossRef]

123. Ebadi, S.V.; Fashandi, H.; Semnani, D.; Rezaei, B.; Fakhrali, A. Electroactive actuator based on polyurethane nanofibers coated with polypyrrole through electrochemical polymerization: A competent method for developing artificial muscles. Smart Mater. Struct. 2020, 29, 045008. [CrossRef]

124. McCormick, M.I.; Fakan, E.P.; Nedelec, S.L.; Allan, B.J.M. Effects of boat noise on fish fast-start escape response depend on engine type. Sci. Rep. 2019, 9, 6554. [CrossRef] [PubMed]

125. Sun, Q.; Han, J.; Li, H.; Liu, S.; Shen, S.; Zhang, Y.; Sheng, J. A Miniature Robotic Turtle With Target Tracking and Wireless Charging Systems Based on IPMCs. IEEE Access 2020, 8, 187156-187164. [CrossRef]

126. Swarrup, J.S.; Ganguli, R.; Madras, G. Studies to improve the actuation capability of low-frequency IPMC actuators for underwater robotic applications. ISSS J. Micro Smart Syst. 2019, 8, 41-47. [CrossRef]

127. Li, M.; Guo, S.; Guo, J.; Hirata, H.; Ishihara, H. Development of a biomimetic underwater microrobot for a father-son robot system. Microsyst. Technol. 2017, 23, 849-861. [CrossRef]

128. Rider, T.; Taite, S.; Intel Corp. Wearable adaptive electroactive polymer fabric. United States patent US 10,334,899, 2 July 2019.

129. Abalyaeva, V.V.; Nikolaeva, G.V.; Dremova, N.N.; Knerel'man, E.I.; Davydova, G.I.; Efimov, O.N.; Ionov, S.G. Electroactive polymer coatings on a modified graphite foil as electrodes for supercapacitors. Prot. Met. Phys. Chem. Surf. 2019, 55, 321-329. [CrossRef]

130. Ashton, M.D.; Appen, I.C.; Firlak, M.; Stanhope, N.E.; Schmidt, C.E.; Eisenstadt, W.R.; Hur, B.; Hardy, J.G. Wirelessly triggered bioactive molecule delivery from degradable electroactive polymer films. Polym. Int. 2021, 70, 467-474. [CrossRef]

131. Hardy, J.G.; Mouser, D.J.; Arroyo-Currás, N.; Geissler, S.; Chow, J.K.; Nguy, L.; Kim, J.M.; Schmidt, C.E. Biodegradable electroactive polymers for electrochemically-triggered drug delivery. J. Mater. Chem. B 2014, 2, 6809-6822. [CrossRef] [PubMed]

132. Ralls, A.; Kumar, P.; Misra, M.; Menezes, P.L. Material Design and Surface Engineering for Bio-implants. JOM 2020, 72, 684-696. [CrossRef]

133. Li, X.; Wang, L.; Zhang, Z.; Kong, D.; Ao, X.; Xiao, X. Electroactive High-Temperature Shape Memory Polymers with High Recovery Stress Induced by Ground Carbon Fibers. Macromol. Chem. Phys. 2019, 220, 1900164. [CrossRef]

134. Zheng, N.; Fang, Z.; Zou, W.; Zhao, Q.; Xie, T. Thermoset shape-memory polyurethane with intrinsic plasticity enabled by transcarbamoylation. Angew. Chem. 2016, 128, 11593-11597. [CrossRef]

135. Basit, A.; L'Hostis, G.; Durand, B. The recovery properties under load of a shape memory polymer composite material. Materialwissenschaft Werkst. 2019, 50, 1555-1559. [CrossRef]

136. Peng, B.; Yang, Y.; Gu, K.; Amis, E.J.; Cavicchi, K.A. Digital light processing 3D printing of triple shape memory polymer for sequential shape shifting. ACS Mater. Lett. 2019, 1, 410-417. [CrossRef]

137. Monwar, M. Nanofiber Fabrication and Applications: Direct Contact Water Desalination \& Energy Harvesting. Electronic Theses and Dissertations, Georgia Southern University, Statesboro, GA, USA, 2020. Available online: https://digitalcommons. georgiasouthern.edu/etd/2096 (accessed on 11 July 2021).

138. Moretti, G.; Papini, G.P.R.; Righi, M.; Forehand, D.; Ingram, D.; Vertechy, R.; Fontana, M. Resonant wave energy harvester based on dielectric elastomer generator. Smart Mater. Struct. 2018, 27, 035015. [CrossRef]

139. Yun, S.; Park, S.; Nam, S.; Park, B.; Park, S.K.; Mun, S.; Lim, J.M.; Kyung, K.-U. An electro-active polymer based lens module for dynamically varying focal system. Appl. Phys. Lett. 2016, 109, 141908. [CrossRef]

140. Qiu, Y. Bistable Electroactive Polymer Material Innovations and Device Explorations; University of California: Los Angeles, CA, USA, 2019.

141. Xie, Y. Applications of Bistable Electroactive Polymers as Rewritable Photonic Paper, Smart Windows and Wearable Pressure Sensors. Ph.D. Thesis, University of California, Los Angeles, CA, USA, 2019.

142. Xie, Y.; Meng, Y.; Wang, W.; Zhang, E.; Leng, J.; Pei, Q. Bistable and Reconfigurable Photonic Crystals—Electroactive Shape Memory Polymer Nanocomposite for Ink-Free Rewritable Paper. Adv. Funct. Mater. 2018, 28, 1802430. [CrossRef] 
143. Sikdar, S.; Siddaiah, A.; Menezes, P.L. Conversion of Waste Plastic to Oils for Tribological Applications. Lubricants 2020, 8, 78. [CrossRef]

144. Qiu, S.; Liu, G.; Li, W.; Zhao, H.; Wang, L. Noncovalent exfoliation of graphene and its multifunctional composite coating with enhanced anticorrosion and tribological performance. J. Alloys Compd. 2018, 747, 60-70. [CrossRef]

145. Wang, Z.; Gu, P.; Zhang, Z. Indentation and scratch behavior of nano-SiO 2 /polycarbonate composite coating at the micro/nanoscale. Wear 2010, 269, 21-25. [CrossRef]

146. Huang, T.; Yeh, J.; Lai, C. Polymer nanocomposite coatings. In Advances in Polymer Nanocomposites; Woodhead Publishing: Sawston, UK, 2012.

147. John, M.; Kalvala, P.R.; Misra, M.; Menezes, P.L. Peening Techniques for Surface Modification: Processes, Properties and Applications. Materials 2021, 14, 3841. [CrossRef] [PubMed]

148. Huang, T.-C.; Yeh, L.-C.; Lai, G.-H.; Huang, B.-S.; Yang, T.-I.; Hsu, S.-C.; Lo, A.-Y.; Yeh, J.-M. Advanced superhydrophobic electroactive fluorinated polyimide and its application in anticorrosion coating. Int. J. Green Energy 2017, 14, 113-120. [CrossRef]

149. Ji, W.F.; Li, C.W.; Yu, S.K.; Chen, P.J.; Chen, H.L.; Chen, R.D.; Chen, B.H.; Hsu, C.L.; Yeh, J.M. Biomimetic electroactive polyimide with rose petal-like surface structure for anticorrosive coating application. Express Polym. Lett. 2017, 11, 635-644. [CrossRef]

150. Youn, J.-H.; Jeong, S.M.; Hwang, G.; Kim, H.; Hyeon, K.; Park, J.; Kyung, K.-U. Dielectric elastomer actuator for soft robotics applications and challenges. Appl. Sci. 2020, 10, 640. [CrossRef]

151. Rahman, M.H.; Helal-An-Nahiyan, M.; Rahman, M.M. Design and Simulation of a Robot-Farmer for Gripping and Cutting Crops. In Proceedings of the International Conference on Mechanical, Industrial and Energy Engineering, Khulna, Bangladesh, 25-26 December 2014; pp. ICMIEE-PI-140110-2-ICMIEE-PI-140110-6.

152. Helal-An-Nahiyan, M.; Rahman, H.; Karim, K.E. Design, Simulation and Mathematical Modeling of a RPR Manipulator for Collecting Waste from Beans. Int. J. Sci. Res. Publ. 2015, 5, 1-6.

153. Rahman, M.H. Catalytic Co-pyrolysis of Pinewood and Waste Plastics for Improving the Selectivity of Hydrocarbons and the Quality of Pyrolysis Oil; Georgia Southern University: Statesboro, GA, USA, 2020.

154. Rahman, M.H.; Bhoi, P.R.; Saha, A.; Patil, V.; Adhikari, S. Thermo-catalytic co-pyrolysis of biomass and high-density polyethylene for improving the yield and quality of pyrolysis liquid. Energy 2021, 225, 120231. [CrossRef]

155. Rahman, M.H.; Bhoi, P.R. An Overview of Non-biodegradable Bioplastics. J. Clean. Prod. 2021, 294, 126218. [CrossRef] 